Research Article

\title{
An S116R Phosphorylation Site Mutation in Human Fibroblast Growth Factor-1 Differentially Affects Mitogenic and Glucose-Lowering Activities
}

\author{
Xue Xia ${ }^{1}$, Ozan S. Kumru ${ }^{2}$, Sachiko I. Blaber ${ }^{1}$, C. Russell Middaugh ${ }^{2}$, Ling Li ${ }^{3}$, \\ David M. Ornitz ${ }^{3}$, Jae Myoung Suh ${ }^{4}$, Annette R. Atkins ${ }^{5}$, Michael Downes ${ }^{5}$, \\ Ronald M. Evans ${ }^{5,6}$, Connie A. Tenorio ${ }^{1}$, Ewa Bienkiewicz ${ }^{1}$, Michael Blaber ' ${ }^{1, *}$ \\ ${ }^{1}$ Department of Biomedical Sciences, Florida State University, Tallahassee, Florida 32306 \\ 2 Department of Pharmaceutical Chemistry, University of Kansas, Lawrence, Kansas 60047 \\ ${ }^{3}$ Department of Molecular Biology and Pharmacology, Washington University School of Medicine, St. Louis, Missouri 63110 \\ $03 \quad{ }^{4}$ Graduate School of Medical Science and Engineering, KAIST, Daejeon 34141, South Korea \\ ${ }^{5}$ Gene Expression Laboratory, Salk Institute for Biological Studies, La Jolla, California 92037 \\ ${ }^{6}$ Howard Hughes Medical Institute, Salk Institute for Biological Studies, La Jolla, California 92037
}

\section{A R T I C L E I N F O}

\section{Article history:}

Received 19 May 2016

Revised 4 September 2016

Accepted 9 September 2016

\section{Keywords}

human fibroblast growth factor-1

heparan sulfate proteoglycan

protein stability

X-ray crystallography

thermodynamics

protein engineering

fibroblast growth factor receptor

\begin{abstract}
A B S T R A C T
Fibroblast growth factor-1 (FGF-1), a potent human mitogen and insulin sensitizer, signals through both tyrosine kinase receptor-mediated autocrine/paracrine pathways as well as a nuclear intracrine pathway. Phosphorylation of FGF-1 at serine 116 (S116) has been proposed to regulate intracrine signaling. Position S116 is located within a 17 amino acid C-terminal loop that contains a rich set of functional determinants including heparin|heparan sulfate affinity, thiol reactivity, nuclear localization, pharmacokinetics, functional half-life, nuclear ligand affinity, stability, and structural dynamics. Mutational targeting of specific functionality in this region without perturbing other functional determinants is a design challenge. S116R is a non-phosphorylatable variant present in bovine FGF-1 and other members of the human FGF family. We show that the S116R mutation in human FGF-1 is accommodated with no perturbation of biophysical or structural properties, and is therefore an attractive mutation with which to elucidate the functional role of phosphorylation. Characterization of S116R shows reduction in NIH 3T3 fibroblast mitogenic stimulation, increase in fibroblast growth factor receptor-1c activation, and prolonged duration of glucose lowering in $o b / o b$ hyperglycemic mice. A novel FGF-1/fibroblast growth factor receptor-1c dimerization interaction combined with non-phosphorylatable intracrine signaling is hypothesized to be responsible for these observed functional effects.
\end{abstract}

๑) 2016 Published by Elsevier Inc. on behalf of the American Pharmacists Association.
Abbreviations used: ANS, 1-anilino-8-naphthalene sulfonate; $C D$, circular dichroism; EPD, empirical phase diagram; FGF-1, fibroblast growth factor-1; FGFR, fibroblast growth factor receptor; $\mathrm{GuHCl}$, guanidine hydrochloride; HS, heparan sulfate; IL-3, interleukin-3; ITC, isothermal titration calorimetry; IV, intravenous; NCS, newborn calf serum; PDB, protein data bank; SOS, sucrose octasulfate; WT, wild-type.

Conflicts of Interest: M.B. is a founding member and owns shares of Trefoil Thera04 peutics, LLC. M.D. and R.M.E are founding members and own shares in Metacrine. This article contains supplementary material available from the authors by request or via the Internet at http://dx.doi.org/10.1016/j.xphs.2016.09.005.

* Correspondence to: Michael Blaber (Telephone: +1-850-644-33611; Fax: +1-850-644-5781).

E-mail address: michael.blaber@med.fsu.edu (M. Blaber).

\section{Introduction}

The mammalian fibroblast growth factors (FGFs) are a family of 22 members of structurally and functionally conserved protein ligands that mediate development, homeostasis, and metabolism (including 4 apparently non-mitogenic members: FGF-11-14). ${ }^{1-4}$ The FGFs signal through 4 main types of FGF-specific tyrosine kinase receptors (FGFR-1-4) and their splice variants. ${ }^{5}$ Unique among the FGFs, FGF-1 is considered a "pan-FGFR activator" as it is able to stimulate all FGFRs and is consequently a broad-specificity human mitogen. ${ }^{6,7}$ Human FGF-1 has relatively low thermostability, ${ }^{8,9}$ and an associated structural dynamics has been postulated to be a key enabler of pan FGFR activation via induced-fit conformational change. ${ }^{10,11}$ 
Heparan sulfate (HS) proteoglycans on the cell surface participate in FGFR activation by contributing to the assembly of a ternary FGF-1|FGFR|HS signal transduction complex. ${ }^{6,12-14}$ HS binding by FGF-1, as determined from lysine protection studies ${ }^{15}$ and X-ray crystallographic analyses, ${ }^{10,16,17}$ identifies a core HS-binding region involving residue position 18 and the C-terminal region 112-128 (referencing the 140 amino acid mature form) (Fig. 1). FGF-1 has a $\beta$-trefoil protein fold, exhibiting a pseudo-3-fold (i.e., $C_{3}$ ) cyclic symmetry ${ }^{18-21}$ and residue positions $112-128$ of the HS-binding site appear as a "structural aneurysm" (having a relative insertion of 2-3 amino acids in comparison with the other 2 symmetry-related loops ${ }^{22}$ ). Deletion of residue positions 120-122 within the HS region significantly diminishes HS affinity, but also yields a remarkable $(\sim 20 \mathrm{~kJ} / \mathrm{mol})$ increase in thermostability-essentially doubling $\Delta G_{\text {unfolding. }}{ }^{22}$ Thus, there is a function/stability and function/foldability tradeoff associated with the structural accommodation of region 112-128 in FGF-1 ${ }^{23}$ and mutations within this region can have a significant effect on the thermostability and structural dynamics of FGF-1 (potentially impacting the pan-FGFR activation properties of FGF-1). The pharmacokinetics (PKs) of intravenous administered FGF-1 describe a 2-compartment model where sequestration by HS on the surface of the vascular endothelium defines the peripheral compartment. ${ }^{24-27}$ The HS affinity of FGF-1 dictates its PK distribution and redistribution kinetics, and therefore influences the clearance kinetics and the mean residence time. ${ }^{27}$ Mutations that diminish the HS affinity of FGF-1 result in a more endocrine-type PK profile; conversely, mutations that increase HS affinity (or mutations that stabilize FGF-1) can enhance the paracrine (i.e., local sequestration) PK profile. ${ }^{27}$ Almost all cell-based assays of FGF-1 function involve interactions with either endogenous HS or exogenously added heparin sulfate; thus, mutations of FGF-1 that affect HS affinity can also affect functional activity through a modulated PK profile. ${ }^{27}$

FGF-1 contains 3 buried cysteines (i.e., reactive thiols) at positions 16,83 , and 117 (C16, C83, and C117). ${ }^{21,28}$ Oxidation of buried thiols can result in an irreversible unfolding pathway that continuously drives the folding equilibrium toward the denatured state. Cysteine substitution mutations in FGF-1 have identified a key interplay between thermostability and thiol reactivity in determining the functional half-life in cell culture, and cysteine mutation can increase the functional half-life by almost 2 orders of magnitude. ${ }^{29,30}$ Similar increases in functional half-life can also be achieved by stabilizing mutations (which also effectively diminish buried thiol reactivity). Stabilizing mutations of FGF-1 can yield a gain of function as regards ERK phosphorylation signaling and $Q$ maintenance of human embryonic stem cells. ${ }^{31}$ Stability mutations can also slow redistribution kinetics in the PK profile ${ }^{27}$; thus, stability and thiol mutations in FGF-1 can both have a pronounced
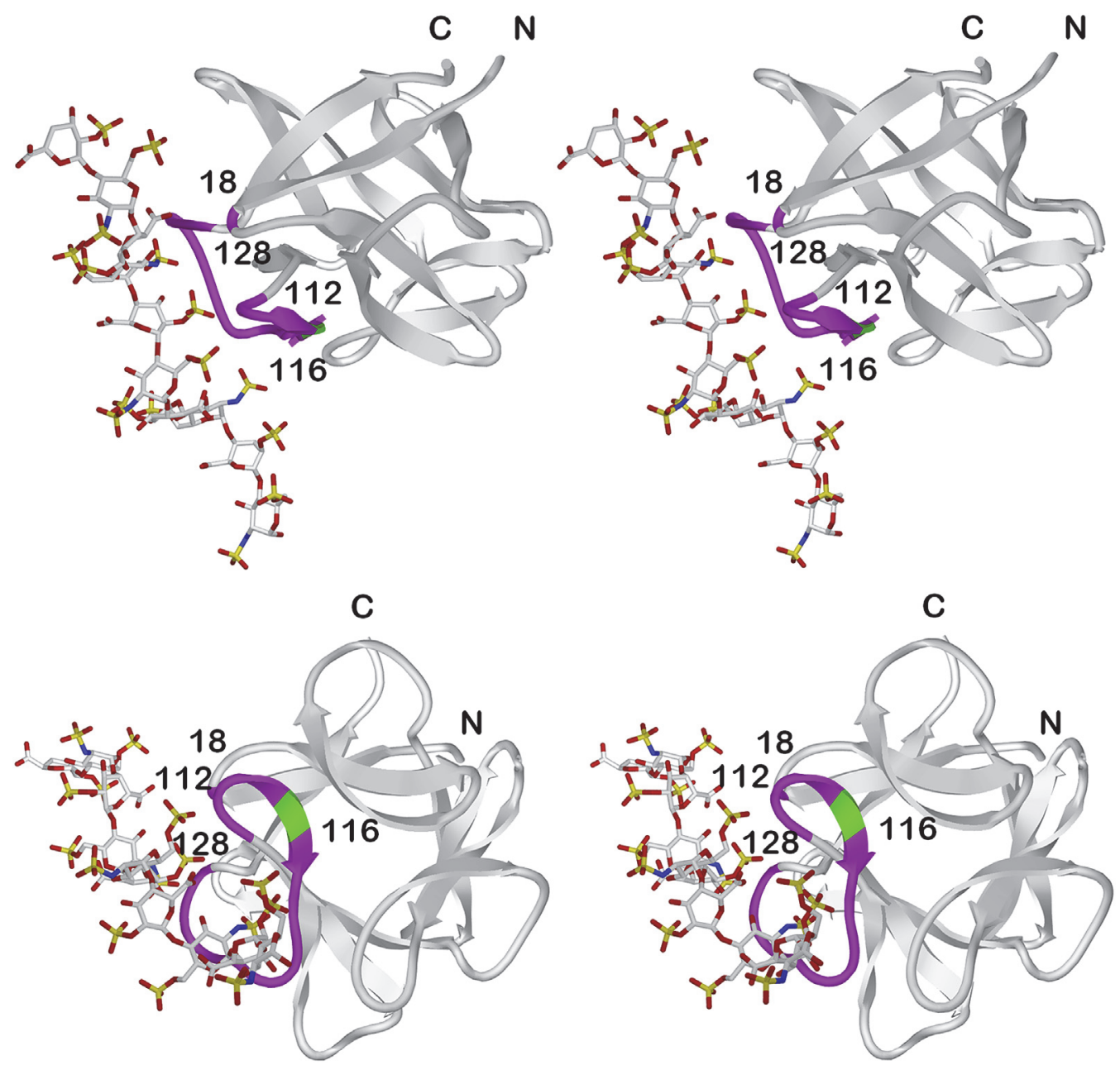

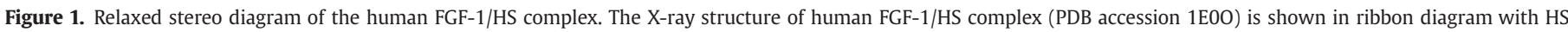

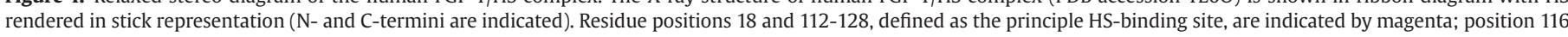

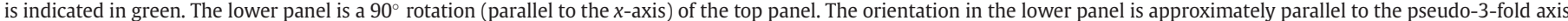
of cyclic symmetry. The "structural aneurysm" (involving amino acid insertions) of region 112-128 in comparison to the symmetry-related loop regions is apparent. 
influence on measured functionality. In this regard, one of the 3 reactive buried thiols in FGF-1 (C117) is also located within the HS-binding region (positions 112-128).

FGF-1 has no traditional secretion signal and is secreted via a non-endoplasmic reticulum/Golgi pathway. ${ }^{32-35}$ Exogenous FGF-1 can also undergo FGFR-mediated endocytosis followed by translocation to the cytosol. ${ }^{36,37}$ FGF-1 contains a nuclear localization signal $^{38,39}$ that directs transport of cytosolic FGF-1 into the nucleus where it can promote DNA synthesis, anti-apoptotic and neurotrophic activities in an intracrine manner. ${ }^{40-42}$ FGF-1 contains a phosphorylation site at serine 116 (S116) located within the HS-binding region (positions 112-128). The functional consequences associated with phosphorylation of FGF-1 are a subject of debate with some reports describing nuclear export and cytoplasmic degradation driven by phosphorylation, ${ }^{43,44}$ while other studies describe no effect on nuclear localization subsequent to phosphorylation, ${ }^{42}$ and yet other studies describe nuclear transport and subsequent enhanced nuclear retention driven by phosphorylation. ${ }^{45}$ The nuclear localization signal(s) of FGF-1 include $\mathrm{N}$-terminal positions $\mathrm{K} 9, \mathrm{~K} 10$, and $\mathrm{K} 12$, and $\mathrm{C}$-terminal positions K100, K101, K112, and K113. ${ }^{39}$ Nucleolin within the nucleus has also been reported to be an interaction partner of FGF-1, affecting phosphorylation and nuclear export. ${ }^{46}$ The recognition of nucleolin by FGF-1 is inhibited by HS, indicating that the nucleolin-binding site, although not yet clearly delineated, overlaps (or resides within) the HS-binding loop. Based on the activity of a K118E mutation, K118 has also been identified as having a functional role in the neurotrophic/anti-apoptotic activity of FGF-1 in PC12 cells. ${ }^{42}$ Such function is postulated to involve an as yet unidentified nuclear ligand, or possibly a conformational alteration. Thus, residue positions associated with nuclear localization, nucleolin recognition, and neurotrophic/anti-apoptotic functionality are also located within the HS-binding region (positions 112-128).

FGF-1 knockout mice develop insulin resistance when stressed by a high-fat diet ${ }^{47}$ and FGF-1 has recently been identified as a novel and potent insulin sensitizer. ${ }^{4}$ Systemic delivery of FGF-1 can effectively reduce blood glucose levels of hyperglycemic mice without inducing hypoglycemia; no effects are seen in normoglycemic mice. The available data indicate that exogenous or endocrinized FGF-1 functions as a potent insulin sensitizer that appears to circumvent the adverse side effects associated with other diabetic therapies. ${ }^{4}$ PK studies of FGF-1 mutants with deletions in the HS-binding site resulting in diminished HS affinity demonstrate a pronounced enhancement of an endocrine PK profile. ${ }^{27}$ Thus, the HS-binding site in region 112-128 likely also plays a critical role in the insulin sensitization function of FGF-1; however, details of the intracrine activity of FGF-1 in such metabolic regulation, including a possible role of phosphorylation at site S116, are unknown.
Overall, residue positions $112-128$ of FGF-1 define a comparatively small C-terminus region that contains a remarkably rich set of diverse functionalities, including determinants of protein stability, HS affinity, thiol and phosphoryl post-translational modification, nuclear localization, nuclear ligand interaction, and structural dynamics (Fig. 2). Thus, a key challenge in structure/ function studies of FGF-1 is to specifically isolate the intended functional effect of a mutational change within this region. For example, a K118E mutation has been described as abolishing the recognition sequence for PKC $\delta$ phosphorylation of $\mathrm{S} 116^{48}$; however, this point mutation also substantially diminishes HS affinity ${ }^{49}$ and destabilizes the protein. ${ }^{50}$ Thus, an unambiguous interpretation of this mutation upon function is confounded by multiple effects. Furthermore, while biophysical properties of structure, stability, and folding are key contributors to FGF-1 functionality, their characterization is rarely included in reports of FGF-1 functional mutations.

In a comparison of the amino acid sequence of FGF-1 from 32 different mammalian species, the S116 phosphorylation site is conserved in all except bovine, where position 116 is arginine (R116; Fig. 2). This naturally occurring phosphorylation site mutation is distinct from reported studies of designed FGF-1 phosphorylation site mutations, which exclusively have utilized alanine (S116A) as a non-phosphorylatable mutant, as well as glutamate and aspartate (S116E and S116D, respectively) as phosphomimetic "non-dephosphorylatable" mutations. ${ }^{42-44,46}$ When comparing all members of the human FGF family, R116 is present at the equivalent position in FGF-3, 6, 8, 17, and 18, while the related $\mathrm{K} 116$ is present in FGF-4 and 5. Among these, FGF- 8,17 , and 18 together comprise the "FGF- 8 subfamily," which regulate the size and positioning of the functional areas of the cerebral cortex (Brodmann's areas). ${ }^{51,52}$ Given the occurrence of S116R in bovine FGF-1 and other members of the human FGF family, and the PAM250 matrix indication that an S to R mutation is essentially statistically neutral, ${ }^{53}$ we postulated S116R to be a naturally preferred non-phosphorylatable mutation. Accordingly, the S116R mutation was constructed in human FGF-1 and a detailed biophysical characterization of the stability and folding properties was performed. These studies show no perturbation of FGF-1, over a broad range of $\mathrm{pH}$ and temperature, in response to the S116R mutation. Additionally, X-ray crystallography analysis shows that the S116R mutation is accommodated with no significant perturbation, either globally or locally, of either the structure or atomic thermal factors. Isothermal titration calorimetry (ITC) with sucrose octasulfate (SOS) (a disaccharide analog of HS), and analytical heparin Sepharose chromatography, also show no significant perturbation of the HS-binding affinity. Based on these results, the S116R mutation has yielded a non-phosphorylatable form of FGF-1 with no perturbation of any other known

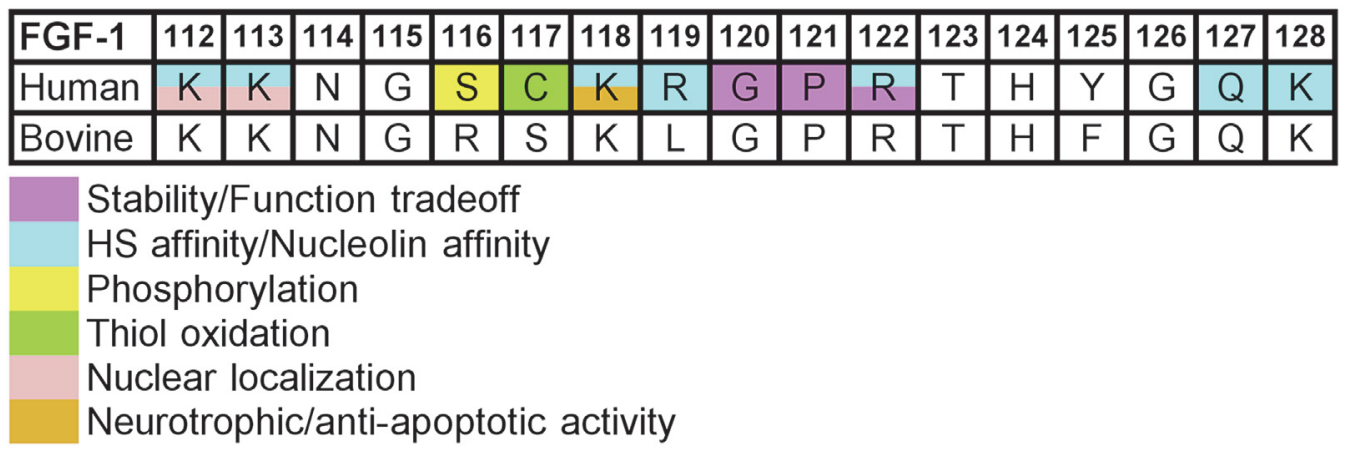

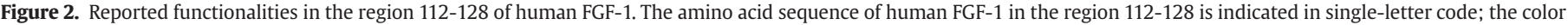
shading indicates reported functionality (see text for references). Also shown is the homologous region from bovine FGF-1. 
determinants of function. An assay of S116R mitogenic activity in NIH 3T3 fibroblasts shows a reduction in function compared to wild-type (WT) FGF-1. BaF3/FGFR-1c and BaF3/FGFR-3c cell signaling/cell survival assays indicate a notable increase in activity, while a BaF3/FGFR-2c assay shows no change in activity. Furthermore, the duration of the glucose-lowering effect of FGF-1 in hyperglycemic $o b / o b$ mice is extended in S116R FGF-1 compared to WT FGF-1. The differential mitogenic and glucose sensitizing effects of the S116R mutation are of particular interest in the possible therapeutic utility of FGF-1 as a novel glucose sensitizer.

\section{Experimental Section}

\section{Mutant Design}

Position S116 in human FGF-1, the site of phosphorylation, is located within the HS-binding region (residue positions 112-128). S116 in FGF-1 is solvent exposed but does not directly interact with HS. Residue position 116 in bovine FGF-1 is R, and consequently eliminates phosphorylation potential. R116 is also naturally present at an equivalent position in FGF-3, 6, 8, 17, and 18, and the related K116 is present in FGF-4 and 5. An overlay of the bovine FGF-1 crystal structure (protein data bank [PDB] accession 1AFC) onto human FGF-1 (PDB accession 1JQZ) yields a root mean square deviation of $0.4 \AA$ for all main chain atoms within $6 \AA$ of position 116 , suggesting that an S116R point mutation in FGF-1 might be accommodated with minimal structural perturbation. The $1 \mathrm{AFC}$ structure of bovine FGF-1 was reported in complex with SOS (a disaccharide HS analog) bound in the HS-binding site, thus suggesting that an S116R mutation is also compatible with HS binding. The S116R mutation was constructed in FGF-1 as a potentially well-tolerated mutation selectively targeting the site of phosphorylation.

\section{Protein Expression and Purification}

Heterologous expression of FGF-1 protein from Escherichia coli utilized a codon-optimized synthetic gene encoding the 140 amino acid form of human FGF-1, plus an N-terminal 6-His tag, in the pET21a(+)|BL21(DE3) expression system (EMD Millipore, Billerica, MA) as previously described. ${ }^{54}$ Residue S116 of FGF-1 was mutated to $\mathrm{R}$ (i.e., S116R) using the QuikChange ${ }^{\mathrm{TM}}$ site-directed mutagenesis kit (Agilent Technologies, Santa Clara, CA), and confirmed by DNA sequencing (Biomolecular Analysis Synthesis and Sequencing Laboratory, Florida State University). Protein expression from a 1 L culture was induced by addition of $1 \mathrm{mM}$ isopropyl- $\beta$-D-thio-galactoside at $\mathrm{OD}_{600}=0.6$, with simultaneous reduction of temperature from $37^{\circ} \mathrm{C}$ to $16^{\circ} \mathrm{C}$, followed by overnight incubation. The expressed His-tagged protein was purified by sequential chromatography on $\mathrm{Ni}$ nitrilotriacetic acid affinity resin (Qiagen, Valencia, CA) and heparin Sepharose (GE Life Sciences, Pittsburgh, PA). The N-terminal His-tag has no effect on the stability or folding properties of FGF-1. ${ }^{55}$ To confirm that the His-tag also has no influence on heparin binding, a non-His-tagged FGF-1 was similarly expressed and purified by sequential chromatography on DE52 anion exchange, heparin Sepharose affinity, and Superdex 75 size exclusion resins (GE Life Sciences). Protein purity was evaluated by gel densitometry of Coomassie Brilliant Blue-stained SDS-PAGE. An extinction coefficient of $E_{280 \mathrm{~nm}}(0.1 \%, 1 \mathrm{~cm})=1.26$ was utilized for concentration determination of both WT and mutant FGF-1 proteins. ${ }^{56,57}$

\section{Isothermal Equilibrium Denaturation}

Purified protein was buffer exchanged into "crystallization buffer" (50 mM sodium phosphate, $100 \mathrm{mM}$ sodium chloride, $10 \mathrm{mM}$ ammonium sulfate, and $2 \mathrm{mM}$ dithiothreitol, $\mathrm{pH}$ 7.5) using 8 kDa molecular weight cutoff membrane tubing (Spectrum Industries, Inc., Chippewa Falls, WI). FGF-1 contains a single buried tryptophan residue (W107) whose fluorescence is internally quenched in the native state, and quenching is comparatively diminished upon unfolding, thereby providing a convenient spectroscopic probe of unfolding. ${ }^{9}$ WT FGF-1 and S116R mutant proteins were equilibrated overnight in crystallization buffer at $25^{\circ} \mathrm{C}(298 \mathrm{~K})$ in $0.1 \mathrm{M}$ increments of guanidine hydrochloride $(\mathrm{GuHCl})$ with a final protein concentration of $5 \mu \mathrm{M}$. Fluorescence intensity was quantified using a Varian Eclipse fluorescence spectrophotometer (Varian Medical Technologies, Palo Alto, CA). Samples were excited at 295 nm, and emission was measured from 304-500 nm. Triplicate scans were collected and averaged and buffer background was collected and subtracted from the protein scans. Fluorescence scans were integrated to quantify the total fluorescence as a function of denaturant concentration. Data were analyzed using a 6 parameter 2-state model $^{58}$ :

$F=\frac{F_{0 N}+S_{N}[D]+\left(F_{0 D}+\left(S_{D}[D]\right)\right) e^{-\left(\Delta G_{0}+m[D]\right) / R T}}{1+e^{-\left(\Delta G_{0}+m[D]\right) / R T}}$

where $[D]$ is the $\mathrm{GuHCl}$ denaturant concentration, $\Delta G_{0}$ and $m$ ( $m$ value) describe the linear function of the unfolding Gibbs energy versus denaturant concentration, $F_{0 N}$ and $F_{0 D}$ are the 0 M denaturant intercepts for the native and denatured state baselines, respectively, and $S_{N}$ and $S_{D}$ are the slopes of the native and denatured state baselines, respectively. The effect of mutation on the stability of the protein $(\Delta \Delta G)$ was calculated taking the difference between the $C_{\mathrm{m}}$ values for WT and mutant protein and multiplying by the average $m$ value, as described by Pace and Scholtz (where a negative value indicates the mutation is stabilizing in comparison to the WT protein ${ }^{59}$ ):

$\Delta \Delta G=\left(C_{\mathrm{m} \cdot \mathrm{WT}}-C_{\mathrm{m} \cdot \text { mutant }}\right)\left(m_{W T}+m_{\text {mutant }}\right) \backslash 2$

\section{Empirical Phase Diagrams}

Purified WT FGF-1 and S116R mutant proteins were dialyzed into $20 \mathrm{mM}$ citrate-phosphate buffer with an overall ionic strength of 0.15 (adjusted by $\mathrm{NaCl}$ ) using an $8 \mathrm{kDa}$ molecular weight cutoff membrane tubing (Spectrum Industries, Inc.).

\section{Far-UV Circular Dichroism Spectroscopy}

Circular dichroism (CD) spectra were collected using a Chirascan-Plus CD spectrometer (Applied Photophysics Ltd, Leatherhead, UK) equipped with a 6-cuvette position Peltier temperature controller (Quantum Northwest, Liberty Lake, WA), an air-cooled $150 \mathrm{~W}$ Xe lamp, and a solid-state avalanche detector. Far-UV CD spectra of triplicate samples at $0.2 \mathrm{mg} / \mathrm{mL}$ were collected in the range of $200-260 \mathrm{~nm}$ in $1 \mathrm{~nm}$ steps and using 0.5 s sampling time and $0.1 \mathrm{~cm}$ path length quartz cuvette. Molar ellipticity at $225 \mathrm{~nm}$ was monitored as a function of temperature from $10^{\circ} \mathrm{C}$ to $87.5^{\circ} \mathrm{C}$ at $2.5^{\circ} \mathrm{C}$ intervals. The heating rate was $1^{\circ} \mathrm{C} / \mathrm{min}$, and the equilibration time at each temperature was $1 \mathrm{~min}$. The molar ellipticity spectrum of the buffer was subtracted from all measurements. All data were subjected to a 3-point Savitzky-Golay smoothing filter using the Chirascan software.

\section{Intrinsic Fluorescence Spectroscopy}

Fluorescence experiments were performed using a PTI QM-40 spectrofluorometer (Photon Technology International, Birmingham, NJ) equipped with a 4-cell position temperature controlled Pelletier (Quantum Northwest, Liberty Lake, WA), a 75 W Xe lamp, 
and an R1527 photomultiplier tube. Samples were excited at 280 $\mathrm{nm}$ and fluorescence emission was monitored from 290 to $380 \mathrm{~nm}$ in $1 \mathrm{~nm}$ increments with a $1 \mathrm{~s}$ integration time at each wavelength. All experiments were performed using $1 \mathrm{~cm}$ quartz cuvettes and $50-100 \mu \mathrm{g} / \mathrm{mL}$ protein. Excitation and emission slits were set to 3 and $4 \mathrm{~nm}$, respectively. The spectrum of the buffer was subtracted from all measurements and the ratio of the intensity at $305 \mathrm{~nm}$ to the intensity at $330 \mathrm{~nm}$ was plotted as a function of temperature.

\section{Static Light Scattering}

Light scattering was quantified by excitation at $280 \mathrm{~nm}$ and measuring the scattered light at the excitation wavelength. Data were acquired concurrent with the intrinsic fluorescence emission using an additional photomultiplier oriented $180^{\circ}$ from the fluorescence photomultiplier. Excitation and emission slits were set at 3 and $0.25 \mathrm{~nm}$, respectively. The light scattering intensity of the buffer was subtracted from all measurements prior to data analysis.

\section{Extrinsic Fluorescence Spectroscopy}

Accessibility of hydrophobic regions in WT FGF-1 and S116R mutant protein as a function of temperature was assessed using 8-anilino-1-naphthalenesulfonate (ANS) (Sigma Chemical, St. Louis, MO). ANS suspended in dimethylsulfoxide was added to FGF-1 (50-100 $\mu \mathrm{g} / \mathrm{mL}$ FGF-1) at a 15:1 molar ratio and incubated in the dark for at least $5 \mathrm{~min}$ at $10^{\circ} \mathrm{C}$. Fluorescence data were measured using an excitation wavelength of $372 \mathrm{~nm}$ and the emission spectrum was monitored from 400 to $600 \mathrm{~nm}$ as a function of temperature $\left(10^{\circ} \mathrm{C}-87.5^{\circ} \mathrm{C}\right)$. The excitation and emission slits were set at 3 and $4 \mathrm{~nm}$, respectively. Step size and integration time were $1 \mathrm{~nm}$ and $0.5 \mathrm{~s}$, respectively. Spectra were collected at $2.5^{\circ} \mathrm{C}$ intervals with a 2 min equilibration time at each temperature. Instrument and cuvette setup were identical to the intrinsic fluorescence experiments. Fluorescence intensity at $480 \mathrm{~nm}$ was plotted as a function of temperature and the emission of the ANS buffer was subtracted from all measurements.

\section{Empirical Phase Diagram Construction}

Three-index empirical phase diagrams (EPDs) were constructed as described ${ }^{60}$ using MiddaughSuite software. Extrinsic fluorescence and $C D$ data were normalized by $\min / \max$ normalization prior to EPD construction.

\section{X-ray Structure Determination}

The FGF-1 S116R mutant protein was concentrated to $6 \mathrm{mg} / \mathrm{mL}$ in crystallization buffer for crystallization trials. Diffraction quality crystals were obtained at $25^{\circ} \mathrm{C}$ incubation from a solution containing $2 \mathrm{M}$ ammonium sulfate, $2 \% \mathrm{vol} / \mathrm{vol}$ polyethylene glycol 400 , and $0.1 \mathrm{M}$ sodium HEPES $\mathrm{pH} 7.5$ using the hanging drop vapor diffusion method. Crystals were mounted by dipping in the mother liquor mixed with $25 \%$ glycerol as a cryoprotectant, and freezing immediately in liquid nitrogen. Diffraction data were collected at the Southeast Regional Collaborative Access Team (Ser-CAT) 22-BM beam line at the Advanced Photon Source at Argonne National Laboratory using a MarCCD225 detector (MarUSA, Evanston, IL). Diffraction data were indexed, integrated, and scaled using the HKL2000 software package. ${ }^{61}$

The WT FGF-1 X-ray coordinates (PDB code 1JQZ) were used as a search model in molecular replacement using the PHENIX ${ }^{62,63}$ software package. Structure refinement of the molecular replacement solution utilized alternate rounds of refinement and model building using PHENIX and COOT $^{64}$ software packages. Five percent of reflection data were set aside as the test set for R-free calculation. ${ }^{65}$ A final round of refinement utilized an omit map calculated using all reflection data. The model coordinates and reflection data have been deposited in the RCSB protein data bank (accession 4XKI). A B-factor comparison between WT FGF-1 and the S116R mutant $\mathrm{C} \alpha$ atoms was performed by averaging B-factors over the 2 S116R molecules in the asymmetric unit and then normalizing this dataset to similarly averaged B-factors for PDB accession 1JQZ for WT FGF-1 (a crystal form isomorphous to S116R). The difference values for the comparison were also calculated as a percentage of the WT FGF-1 B-factors.

\section{ITC of SOS Binding}

Purified protein was exchanged into "ADA buffer" (20 mM N-2acetamido iminodiacetic acid, $100 \mathrm{mM} \mathrm{NaCl}, \mathrm{pH}$ 7.4) using $8 \mathrm{kDa}$ molecular weight cutoff dialysis tubing (Spectrum Industries, Inc.). WT FGF-1 and S116R mutant protein $(60 \mu \mathrm{M})$ was titrated against $750 \mu \mathrm{M}$ SOS at $25^{\circ} \mathrm{C}$ in an ITC200 microcalorimeter (Malvern Instruments, Westborough, MA). Titration utilized 31 injections, with an initial injection volume of $0.5 \mu \mathrm{L}$ and subsequent injections of $1 \mu \mathrm{L}$. Three independent datasets were collected for each protein sample to calculate average and standard deviation values. The titration curve after baseline subtraction was fitted with a single ligand-binding site model using the manufacturer's software (OriginLab Corporation, Northampton, MA).

\section{Analytical Heparin Sepharose Chromatography}

The affinity of WT FGF-1 and S116R for heparin Sepharose was evaluated using a $10 \mathrm{~mL}$ analytical heparin Sepharose CL-6B column on an AKTA FPLC workstation (GE Life Sciences). Approximately $100 \mu \mathrm{g}$ of protein was loaded in crystallization buffer and eluted with a linear gradient of $0-2.0 \mathrm{M} \mathrm{NaCl}$ over $20 \times$ column volume. Absorbance was monitored at $280 \mathrm{~nm}$ and absorbance and conductivity traces as a function of eluent volume were quantified to determine concentration of $\mathrm{NaCl}$ associated with the elution peak.

\section{NIH 3 T3 Fibroblast Mitogenic Assay}

The mitogenic activity of WT FGF-1 and S116R toward NIH 3T3 fibroblasts, quantified by direct cell counting, was performed following a previously described procedure. ${ }^{66} \mathrm{NIH}$ 3T3 fibroblast cells express HS proteoglycan, and no heparin sulfate was added in this assay. Briefly, NIH 3T3 fibroblasts were initially plated in Dulbecco's modified Eagle's medium (American Type Culture Collection, Manassas, VA) supplemented with $10 \%$ (vol/vol) newborn calf serum (NCS) (Sigma), $100 \mathrm{U}$ of penicillin, $100 \mathrm{mg}$ of streptomycin, $0.25 \mathrm{mg}$ of Fungizone ${ }^{\mathrm{TM}}$, and $0.01 \mathrm{mg} / \mathrm{mL}$ of gentamicin (Gibco, Carlsbad, CA) ("serum-rich medium") in T75 tissue culture flasks (Fisher, Pittsburgh, PA). The cultures were incubated at $37^{\circ} \mathrm{C}$ with $5 \%$ ( $\mathrm{vol} / \mathrm{vol}$ ) $\mathrm{CO}_{2}$ supplementation. At $~ 80 \%$ cell confluence, the cells were washed with $5 \mathrm{~mL}$ of Tris-buffered saline $(0.14 \mathrm{M} \mathrm{NaCl}, 5.1 \mathrm{mM}$ $\mathrm{KCl}, 0.7 \mathrm{mM} \mathrm{Na}_{2} \mathrm{HPO}_{4}, 24.8 \mathrm{mM}$ Tris base $\mathrm{pH}$ 7.4) and subsequently treated with $5 \mathrm{~mL}$ of a $0.025 \%$ ( $\mathrm{vol} / \mathrm{vol}$ ) trypsin solution (Invitrogen Corporation, Carlsbad, CA). The trypsinized cells were then seeded in T25 tissue culture flasks at a density of $3.0 \times 10^{4} \mathrm{cells} / \mathrm{cm}^{2}$ (representing $\sim 20 \%$ confluence). Cell quiescence was initiated by serum starvation in Dulbecco's modified Eagle's medium with 0.5\% NCS, $100 \mathrm{U}$ of penicillin, $100 \mathrm{mg}$ of streptomycin, $0.25 \mathrm{mg}$ of Fungizone $^{\mathrm{TM}}$, and $0.01 \mathrm{mg} / \mathrm{mL}$ of gentamicin. Cultures were incubated for $48 \mathrm{~h}$ at $37^{\circ} \mathrm{C}$, the medium was then decanted and replaced with fresh medium supplemented with WT or S116R FGF-1 protein from 0.006 to $630 \mathrm{nM}\left(1.0 \times 10^{2}\right.$ to $\left.1.0 \times 10^{7} \mathrm{pg} / \mathrm{mL}\right)$, as well as $10 \% \mathrm{NCS}$ as a positive control, and the cultures were incubated for an additional $48 \mathrm{~h}$. After this incubation, the medium was decanted and the 
cells were washed with $1 \mathrm{~mL}$ of Tris-buffered saline. One milliliter of $0.025 \%$ trypsin was then added to release the cells from the flask surface; subsequently, $2 \mathrm{~mL}$ of serum-rich medium was added to dilute and inhibit the trypsin. Triplicate cell samples were counted using a Coulter Counter (Beckman Coulter, Brea, CA). Dose response experiments were performed in triplicate.

\section{BaF3/FGFR Signaling/Cell Viability Assay}

BaF3 cells are dependent on interleukin 3 (IL-3) for growth; however, this dependence can be replaced by ligands for receptor tyrosine kinases upon transfection and expression of the appropriate receptor tyrosine kinase. ${ }^{67,68} \mathrm{BaF} 3$ cells do not express FGFRs but can be propagated in the presence of FGF when transfected to express FGFRs. ${ }^{67,69}$ BaF3 cell lines independently expressing FGFR1c, FGFR-2c, and FGFR- $3 c^{6}$ were used to quantify receptor activation/cell viability activity by WT FGF-1 and the S116R mutant protein. BaF3 cells lack membrane-bound HS proteoglycan, and heparin sulfate $(1 \mu \mathrm{g} / \mathrm{mL})$ was added to the assay to promote formation of the ternary FGF-1/FGFR/HS signal transduction complex. Cells were initially maintained in Roswell Park Memorial Institute 1640 medium (Sigma Chemical) supplemented with 10\% NCS (Sigma Chemical), $0.5 \mathrm{ng} / \mathrm{mL}$ murine recombinant IL-3 (mIL-3; PeproTech, Inc., Rocky Hill, NJ), 2 mM L-glutamine, penicillinstreptomycin, and $50 \mu \mathrm{M} \beta$-mercaptoethanol ("BaF3 culture medium”), and G418 antibiotic (600 $\mu \mathrm{g} / \mathrm{mL})$. BaF3 cells expressing FGFR were washed twice in BaF3 "assay medium" ("culture medium" lacking IL-3) and plated at a density of $40 \times 10^{3}$ cells/well in a 96-well assay plate in assay medium containing $2 \mu \mathrm{g} / \mathrm{mL}$ heparin sulfate and $0.02-5 \mathrm{nM}\left(3.18 \times 10^{2}\right.$ to $\left.7.95 \times 10^{4} \mathrm{pg} / \mathrm{mL}\right)$ WT FGF- 1 or S116R mutant protein. The cell viability for FGFR expressing BaF3 cells was assayed using a water soluble tetrazolium salt reagent (CCK-8 kit; Mayflower Bioscience, St. Louis, MO). The cells were incubated for $36 \mathrm{~h}$ and cell viability was determined by adding 20 $\mu \mathrm{L}$ of CCK- 8 reagent. Cells were incubated for $5 \mathrm{~h}$ and reduced CCK-8 was quantified by measuring absorbance between 450 and $490 \mathrm{nM}$ on a Microplate Reader.

\section{Blood Glucose Regulation in ob/ob Mice}

Mice were housed in a temperature-controlled environment with a $12 \mathrm{~h}$ light/12 h dark cycle and handled in accordance with Salk IACUC guidelines complying with US legislation. Male $o b / o b$ mice (B6.V-Lep ${ }^{\mathrm{ob}} / \mathrm{J}$; The Jackson Laboratory, Bar Harbor, ME) received a standard diet (MI laboratory rodent diet Teklad 5001; Envigo, Cambridgeshire, UK) and acidified water ad libitum. Blood glucose levels were monitored using an OneTouch Ultra glucometer (Lifescan Laboratory, Inc., Skokie, IL) in duplicate samples collected by tail bleeding. An initial non-fasting hyperglycemic condition was confirmed on blood glucose level $>300 \mathrm{mg} / \mathrm{dL}$. WT FGF1 or S116R mutant $(0.1 \mathrm{mg} / \mathrm{mL}$ in PBS) was injected sub-cutaneous at $0.5 \mathrm{mg} /$ $\mathrm{kg}$, with PBS injected as control, and blood glucose levels monitored as a function of time.

\section{Results}

\section{Stability and Folding Properties}

The Gibbs energy of unfolding $(\Delta G)$, folding cooperativity ( $m$ value), and $\mathrm{GuHCl}$ concentration at the midpoint of denaturation $\left(C_{\mathrm{m}}\right)$ derived from IED analyses are indistinguishable between WT FGF-1 and the S116R mutant (Table 1; Supplementary Fig. S1). EPDs for WT FGF-1 and S116R were determined over a pH range of 3.08.0, and a temperature range of $10^{\circ} \mathrm{C}-87.5^{\circ} \mathrm{C}$, quantifying $\mathrm{CD}$, intrinsic fluorescence, static light scattering, and ANS dye-binding properties. The data are presented with $\mathrm{EPDs}^{70}$ utilizing RGB color mapping to simultaneously compare 3 different properties (Fig. 3 and Supplementary Fig. S2). The CD signal at $225 \mathrm{~nm}$ (monitoring effects upon protein secondary structure) for both WT FGF-1 and S116R mutants are essentially indistinguishable over the entire $\mathrm{pH}$ and temperature range. The $\mathrm{CD}$ signal for both proteins in the range of $\mathrm{pH} 3.0-4.0$ is consistent with an unfolded state (i.e., acid-induced denaturation at all temperatures). The CD signal over pH 5.0-8.0 indicates a highly cooperative unfolding transition in the region of $40^{\circ} \mathrm{C}-47.5^{\circ} \mathrm{C}$, with a $\mathrm{pH}$ of maximum stability around 7.0, for both proteins. The intrinsic fluorescence signal for both WT FGF1 and S116R mutants is contributed by a shared set of $1 \mathrm{~W}$ and $8 \mathrm{Y}$ residues principally located at buried positions, distributed throughout the structure, and which serve as a probe of tertiary structure conformational change. Both WT FGF-1 and S116R mutants exhibit an intrinsic fluorescence at $\mathrm{pH} 3.0$ and 4.0 consistent with a denatured state and in agreement with the $C D$ data. The intrinsic fluorescence data for both proteins indicate a highly cooperative transition between native and denatured tertiary structure between $40^{\circ} \mathrm{C}$ and $47.5^{\circ} \mathrm{C}$ and over the $\mathrm{pH}$ range 5.0-8.0. The intrinsic fluorescence data agree well with the $C D$ spectra, indicating concomitant secondary and tertiary structure unfolding transitions essentially indistinguishable between both proteins.

There is no significant change in light scattering for both WT FGF-1 and S116R mutant proteins at $\mathrm{pH} 3.0$ and 4.0, indicating that the acid-induced denatured state does not aggregate with temperature (consistent with visual inspection for both proteins). Over pH 5.0-8.0, as temperature elevates above the cooperative unfolding transition, there is a significant increase in light scattering intensity corresponding to aggregate formation (this is followed at even higher temperature by a reduction in light scattering intensity as macroscopic protein aggregation takes place). The light scattering|temperature-induced aggregation of unfolded WT FGF-1 and S116R are essentially indistinguishable. ANS binding, as a probe of partially folded or molten globule states, was utilized in constructing a supplemental EPD substituting ANS binding for intrinsic fluorescence (Supplementary Fig. S2). The WT FGF-1 and S116R mutants have similar ANS binding signals at each temperature and pH condition.

Taken together, these data indicate that WT FGF-1 and S116R mutants are essentially indistinguishable with regard to thermodynamic parameters of stability, folding cooperativity, and changes

Table 1

Isothermal Equilibrium Denaturation Parameters for FGF-1 S116R

\begin{tabular}{|c|c|c|c|c|}
\hline Protein & $\Delta G(\mathrm{~kJ} \backslash \mathrm{mol})^{\mathrm{a}}$ & $m$ value $(\mathrm{kJ} / \mathrm{mol} / \mathrm{M})^{\mathrm{b}}$ & $C_{\mathrm{m}}(\mathrm{M})^{\mathrm{c}}$ & $\Delta \Delta G(\mathrm{~kJ} \backslash \mathrm{mol})^{\mathrm{d}}$ \\
\hline WT FGF-1 & $25.6 \pm 0.2$ & $20.8 \pm 0.2$ & $1.23 \pm 0.01$ & - \\
\hline FGF-1 S116R & $25.1 \pm 0.5$ & $20.2 \pm 0.3$ & $1.24 \pm 0.01$ & -0.2 \\
\hline
\end{tabular}

${ }^{\text {a }} \Delta G$ is the difference in Gibb's energy between the denatured state and the native state at 0 M denaturant; positive values denote spontaneous folding.

b $m$ value is the linear sensitivity of $\Delta G$ to denaturant concentration.

${ }^{c} C_{\mathrm{m}}$ is the midpoint of denaturation, the concentration of denaturant where $\Delta G=0$.

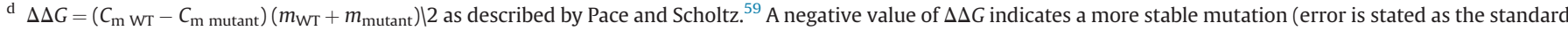
deviation from 3 independent experiments). 

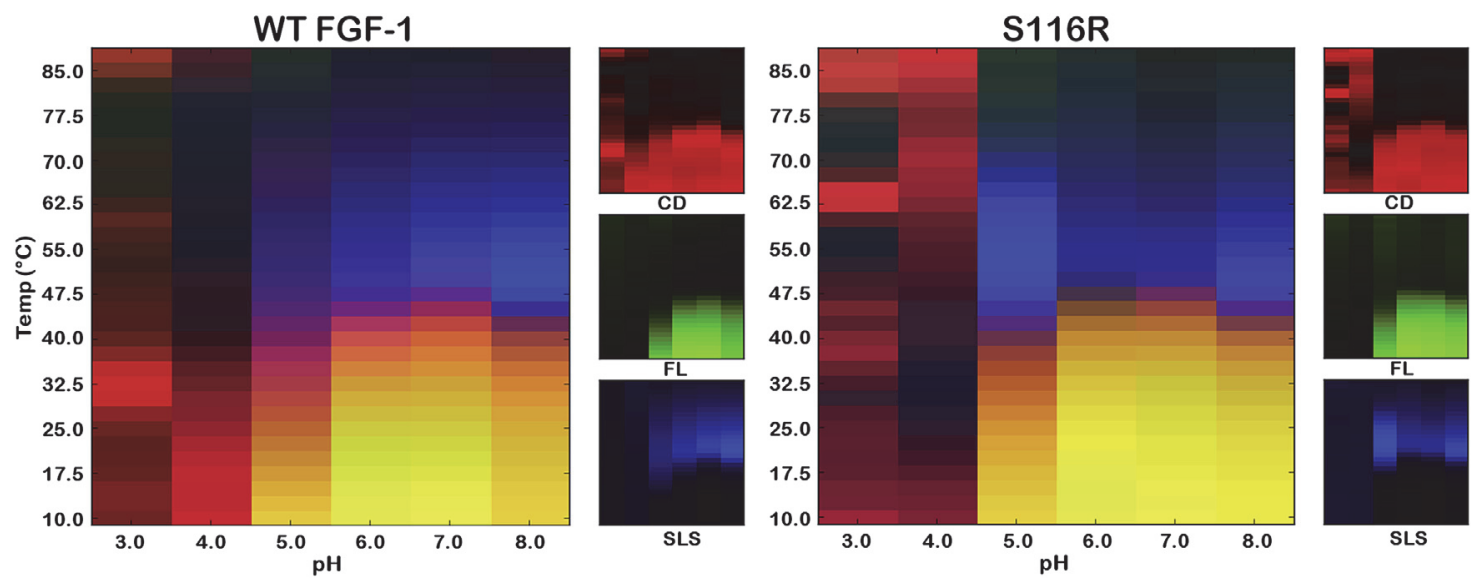

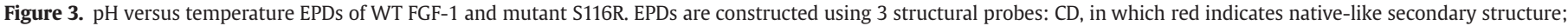

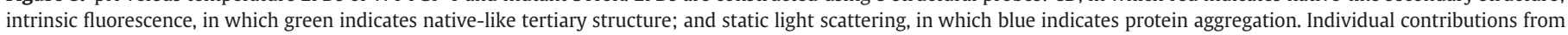
each probe are shown on the right, with the large images showing the additive overlay of all probe data.

in secondary structure, tertiary structure, and aggregation, in response to a wide range of variation in $\mathrm{pH}$ and temperature.

\section{X-ray Crystal Structure Analysis}

The S116R mutant protein crystallized in space group C222 with 2 molecules (A and B) in the asymmetric unit, isomorphous to His-tagged WT FGF-1 (PDB code 1JQZ and 1RG8). ${ }^{71,72}$ Molecular replacement using the WT FGF-1 structure (1JQZ) as a search model was straightforward, and the mutant S116R structure was refined to acceptable stereochemistry and crystallographic residuals (Table 2). Unambiguous $2 \mathrm{Fo}-\mathrm{Fc}$ electron density (contoured at $1 \sigma$ ) was present for the mutant R116 side chain in both molecules in the

Table 2

X-Ray Diffraction Data Collection, Processing, and Structure Refinement of S116R Mutation

\begin{tabular}{|c|c|}
\hline Protein & S116R \\
\hline \multicolumn{2}{|l|}{ Data collection and processing } \\
\hline Space group & $\mathrm{C} 222_{1}$ \\
\hline \multicolumn{2}{|l|}{ Cell constants } \\
\hline$a(\AA)$ & 75.6 \\
\hline$b(\AA)$ & 96.3 \\
\hline$c(\AA)$ & 109.5 \\
\hline$\alpha, \beta, \gamma\left({ }^{\circ}\right)$ & 90 \\
\hline Max resolution $(\AA ̊)$ & 2.00 \\
\hline Mosaicity range $\left(^{\circ}\right)$ & 0.43 \\
\hline Redundancy & 14.9 \\
\hline Mol $\backslash A S U$ & 2 \\
\hline Matthews coefficient $\left(\AA^{3} \mid \mathrm{Da}\right)$ & 2.98 \\
\hline Total reflections & 408,090 \\
\hline Unique reflections & 27,441 \\
\hline $\mathrm{I} \mid \sigma$ (overall) & 44.5 \\
\hline $\mathrm{I} \mid \sigma$ (highest shell) & 8.3 \\
\hline Completion overall (\%) & 99.9 \\
\hline Completion highest shell (\%) & 99.7 \\
\hline R-merge overall (\%) & 7.8 \\
\hline R-merge highest shell (\%) & 40.4 \\
\hline \multicolumn{2}{|l|}{ Refinement } \\
\hline Non-hydrogen protein atoms & 2395 \\
\hline Solvent molecules\ion & 272 \\
\hline$R_{\text {cryst }}(\%)$ & 0.175 \\
\hline$R_{\text {free }}(\%)$ & 0.215 \\
\hline Root mean square deviation bond length $(\AA)$ & 0.007 \\
\hline Root mean square deviation bond angle $\left(^{\circ}\right)$ & 1.07 \\
\hline Ramachandran favored (\%) & 96.2 \\
\hline Ramachandran outliers (\%) & 0.7 \\
\hline PDB accession & $4 \mathrm{XKI}$ \\
\hline
\end{tabular}

asymmetric unit. In the case of molecule A, this density extended throughout each atom of the mutant $R$ side chain, whereas in molecule B the density was poor after the side chain $C \gamma$ but did allow unambiguous assignment of the mutant $\mathrm{R}$ side chain $\chi^{1}$ and $\chi^{2}$ rotamer angles. Although the WT FGF-1 Ser at position 116 adopts a $\chi^{1}=+70^{\circ}$ (i.e., gauche-) rotamer, the mutant Arg 116 residue adopts a $\chi^{1}=-60^{\circ}$ (i.e., gauche + ) rotamer in molecules $\mathrm{A}$ and $B$. In molecule $A$ of the asymmetric unit, the mutant R116 adopts the common $180^{\circ}$ (i.e., trans) side chain $\chi^{2}-\chi^{3}$ angles. In molecule $B$, while the $\chi^{1}$ and $\chi^{2}$ angles are identical to those of the mutant $\mathrm{R}$ in molecule $\mathrm{A}$, the $\chi^{3}$ angle refined as $+60^{\circ}$ (gauche-) although electron density for the terminal atoms of this side chain was poor. While the local environment surrounding R116 in molecule $B$ is free of crystal contacts, there are some alternative rotamers of R116 in molecule A precluded by nearby crystal contacts. In total, the structural data indicate that the mutant R116 side chain in both molecules of the asymmetric unit adopt a rotamer having gauche $+\chi^{1}$ and trans $\chi^{2}$ angles, but with side chain flexibility beyond these positions, consistent with the solvent-exposed nature of position 116 in FGF-1.

An overlay of all backbone atoms of WT FGF-1 (1JQZ) and the S116R mutant (molecule $A$ in both structures) yields a root mean square deviation of $0.34 \AA$, and $0.13 \AA$ for all residue positions within $6 \AA$ of the site of mutation (Fig. 4). This structural overlay shows that the mutant $\mathrm{R}$ side chain is accommodated with no discernable structural perturbation of either the local or global structure. Potential effects of the S116R mutation on the structural dynamics of FGF-1 were evaluated by a B-factor analysis of C $\alpha$ atoms. This analysis shows no discernable alteration of main chain atomic thermal motion (either locally or global) in response to mutation (Supplementary Fig. S3), indicating that the S116R mutation has also been accommodated with negligible effect on the structural dynamics of FGF-1.

\section{SOS and Heparin Sepharose Affinity}

The stoichiometry, dissociation constant, and thermodynamics of binding between WT FGF-1 and SOS (a disaccharide HS analog), as determined by ITC, are listed in Table 3. A comparison of Histagged versus non-His-tagged WT FGF-1 indicates that the Histag has no effect on the $K_{\mathrm{D}}$ of SOS binding. The ITC data for the interaction between WT FGF-1 and SOS are in excellent agreement with other published studies of the binding of SOS and related disaccharide HS analogs. ${ }^{14,22,73}$ The S116R mutant exhibits a minor 

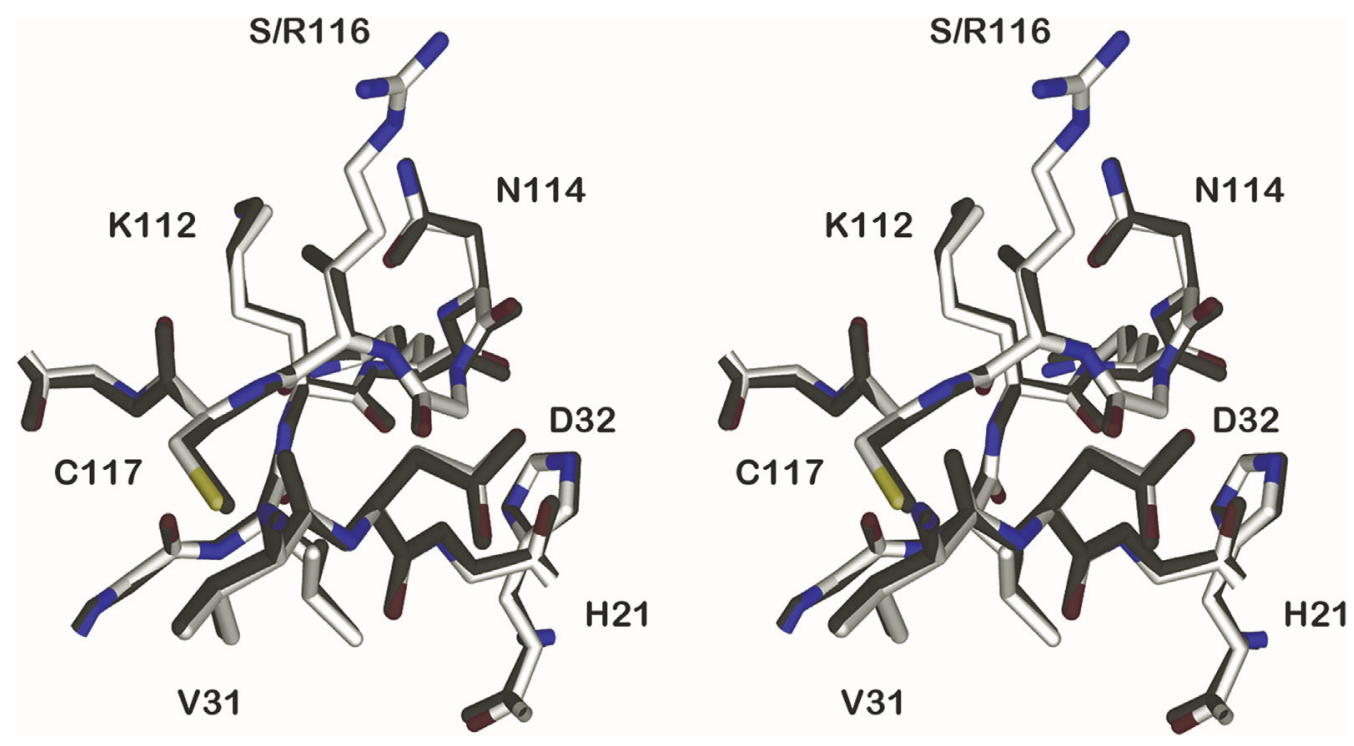

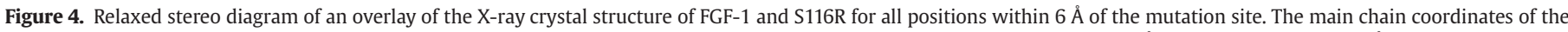

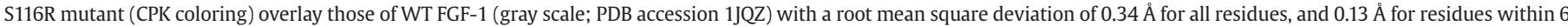

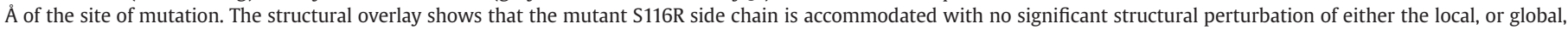
structure.

enhancement in binding affinity for SOS (corresponding to a change in binding energy of $\Delta \Delta G-0.9 \mathrm{~kJ} / \mathrm{mol}$ ). Analytical chromatography with heparin Sepharose shows that WT FGF-1 and the S116R mutant exhibit indistinguishable chromatograms when eluted with an $\mathrm{NaCl}$ gradient; in each case, the bound protein eluted at $1.28 \mathrm{M} \mathrm{NaCl}$ (Supplementary Fig. S4). Thus, the apparent minor increase in SOS affinity for the S116R mutant does not result in any significant alteration of affinity for heparin Sepharose.

Functional Characterization by 3T3 Fibroblast Mitogenic Assay, BaF3/FGFR Receptor Signaling/Cell Viability Assay, and Glucose Regulation Assay

The mitogenic activity of WT FGF-1 and S116R toward NIH 3T3 fibroblasts, assayed by direct counting of cell number, is shown in Figure 5. The assay quantifies mitogenic activity over the range of 2-7 $\log \mathrm{pg} / \mathrm{mL}$. Fitted sigmoid functions for both WT FGF-1 and S116R indicate essentially identical $\mathrm{EC}_{50}$ values $(5.8 \pm 0.3$ and $5.7 \pm$ $0.2 \log \mathrm{pg} / \mathrm{mL}$, respectively), indicating an equivalent concentration required for half-maximal mitogenic stimulation. However, the maximum achievable cell stimulation for the S116R mutant is only $\sim 80 \%$ that of WT FGF-1 ( $p=0.05$, while the internal $10 \%$ NCS controls between WT FGF-1 and S116R are statistically indistinguishable).

FGF-1 is a pan-FGFR activator (although NIH 3T3 cells are known to express FGFR- 1 and $2^{74-76}$ but not FGFR-3, ${ }^{77}$ while expression of FGFR4 has not been reported). Stimulation of FGFR-1, 2, and 3 (isoform c in each case) was evaluated in transformed BaF3 cells. The receptor signaling/cell viability assay of BaF3 cells expressing FGFR-1c with WT FGF-1 and S116R mutant in the presence of added heparin is shown in Figure 6a. The BaF3/FGFR-1c cell system exhibits a receptor signaling/cell viability response over a concentration range of $2.5-5.0 \mathrm{log} \mathrm{pg} / \mathrm{mL}$. This increase in sensitivity compared to the NIH 3T3 assay is attributed to the addition of exogenous HS in the BaF3 assay (required for this cell line). Exogenously added HS can increase the signaling response of FGF-1 with NIH 3T3 fibroblasts by 2 orders of magnitude, ${ }^{29}$ and it is therefore critical when comparing mutant and WT FGF-1 activity to employ identical HS concentrations. In this regard, the NIH 3T3 assay comparing WT FGF-1 and S116R is performed under identical conditions of endogenous HS concentration, and the BaF3 assay comparing WT FGF-1 and S116R is performed under identical conditions of $1 \mu \mathrm{g} / \mathrm{mL}$ exogenously added heparin sulfate. In the BaF3/FGFR-1c assay, the S116R mutant achieves a maximum stimulation at $313 \mathrm{pM}$ (3.72 $\log \mathrm{pg} / \mathrm{mL}$ ) and with an apparent inhibitory effect at higher concentrations. Such inhibitory effects at high concentrations of FGF-1 have previously been described. ${ }^{78,79}$ In contrast, WT FGF-1 achieves maximal stimulation at the highest concentration (5000 pM; $4.92 \log \mathrm{pg} / \mathrm{mL}$ ). The receptor signaling/ cell viability activity of WT FGF-1 and S116R mutants with BaF3/ FGFR-2c has a similar range of sensitivity as the BaF3/FGFR-1c (i.e., 2.5-5.0 $\log \mathrm{pg} / \mathrm{mL}$; Fig. 6b); however, unlike FGFR-1c the S116R mutant exhibits an essentially indistinguishable FGFR-2c signaling/cell viability activity compared to WT FGF-1. The BaF3/ FGFR-3c assay demonstrates enhanced activity for the S116R mutant compared to WT FGF-1 and is even more pronounced than that seen with BaF3/FGFR-1c (Fig. 6c).

The effects of subcutaneous injections of FGF-1 and S116R on blood glucose levels in hyperglycemic ob/ob mice are shown in Figure 7. WT FGF-1 and S116R are equally effective at normalizing

Table 3

Isothermal Titration Calorimetry Parameters for WT FGF-1 and S116R Mutant Proteins Binding Sucrose Octasulfate at 298 K

\begin{tabular}{|c|c|c|c|c|c|c|}
\hline Protein & $N$ (site) & $K_{\mathrm{D}}(\mu \mathrm{M})$ & $\Delta H(\mathrm{~kJ} / \mathrm{mol})$ & $\Delta S(\mathrm{~J} / \mathrm{mol} / \mathrm{K})$ & $-T \Delta S(\mathrm{~kJ} / \mathrm{mol})$ & $\Delta G(\mathrm{~kJ} / \mathrm{mol})$ \\
\hline WT FGF-1 & $0.92 \pm 0.05$ & $3.94 \pm 0.19$ & $-31.4 \pm 0.4$ & $-1.84 \pm 0.96$ & 0.55 & -30.9 \\
\hline WT FGF-1 ${ }^{\mathrm{a}}$ & $0.98 \pm 0.04$ & $3.85 \pm 0.09$ & $-29.1 \pm 0.3$ & $5.94 \pm 0.75$ & -1.77 & -30.9 \\
\hline FGF-1 S116R & $0.94 \pm 0.04$ & $2.72 \pm 0.19$ & $-29.5 \pm 0.3$ & $7.66 \pm 1.63$ & -2.28 & -31.8 \\
\hline
\end{tabular}

${ }^{\text {a }}$ No $N$-terminal $6 \times($ His $)$ tag. 


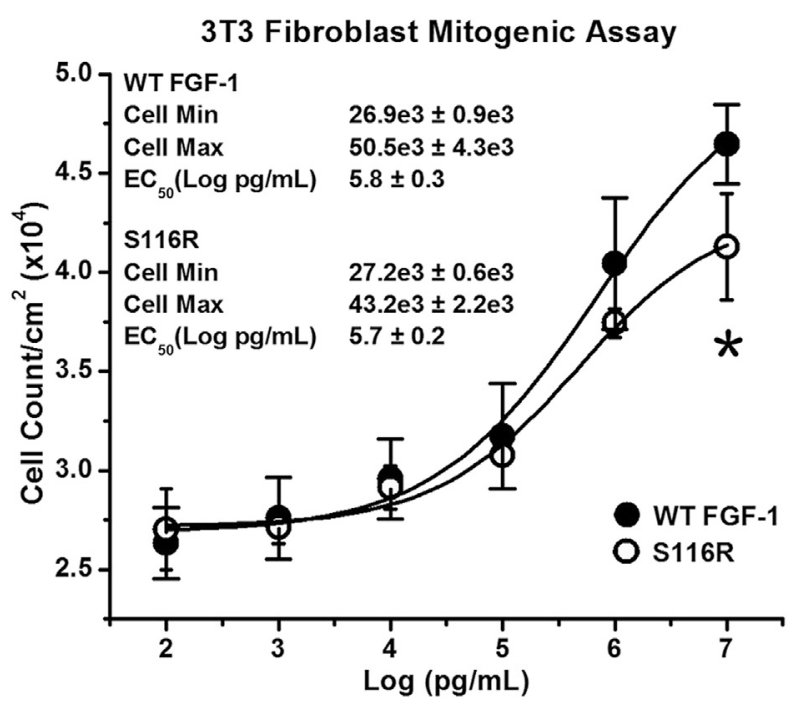

Figure 5. Mitogenic assay of WT FGF-1 and S116R mutant protein. A dose-response mitogenic activity of WT FGF-1 and S116R with NIH 3T3 fibroblasts was determined from direct cell counts $\left({ }^{*} p=0.05\right)$.

random fed blood glucose levels within $24 \mathrm{~h}$, and display comparable effects for 3 days post injection. However, while the effects of WT FGF-1 are essentially lost by day 5 , significant reductions in blood glucose are seen through day 7 with S116R injections $(p=0.015)$.

\section{Discussion}

The functional consequence of the phosphorylation of S116 in FGF-1 by PKC $\delta$, particularly with regard to cytoplasmic/nuclear localization and regulation of intracrine activity, is an area of active interest. Więdłocha et al. constructed S116A and S116E mutations in FGF-1 to produce non-phosphorylatable and phosphomimetic forms, respectively. ${ }^{43,44}$ These authors reported that the S116E phosphomimetic form was exported to the cytosol after nuclear translocation and subsequently degraded. Renaud et al. constructed S116A and S116D mutations of FGF-1 for the same purpose ${ }^{42}$ and reported that while phosphorylation abrogates the FGF-1-mediated protection against p53-dependent apoptosis, there was no significant effect on nuclear localization in PC12 cells. However, the effects of such mutations on other biophysical and structural properties known to critically influence function were not determined.

S116R is a commonly observed phosphorylation site variant in the FGF family. Detailed biophysical data reported herein show that the S116R mutation is indistinguishable from WT FGF-1 in stability profile (over a wide range of temperature and $\mathrm{pH}$ ), folding cooperativity, solubility, and aggregation properties. The X-ray structure shows that the S116R mutation is accommodated with no detectable structural perturbation or alteration in B-factor-based structural dynamics. A minor increase in SOS affinity (corresponding to a change in binding energy of $0.9 \mathrm{~kJ} / \mathrm{mol}$ ) is observed with titration calorimetry; however, no change in HS affinity is observed with analytical heparin Sepharose chromatography. Therefore, the S116R mutation is arguably an ideal mutant to probe the functional consequences of eliminating the phosphorylation site of human FGF-1 without perturbing other known functional determinants, and using an evolutionarily observed variation in the FGF family.

The role of phosphorylation of FGF-1 in the measured BaF3 cell response is unclear; however, a potential intracrine pathway would be identical in all the BaF3 assays. The FGFR-2c result suggests that any intracrine activity of FGF-1 in the BaF3 system is insensitive to
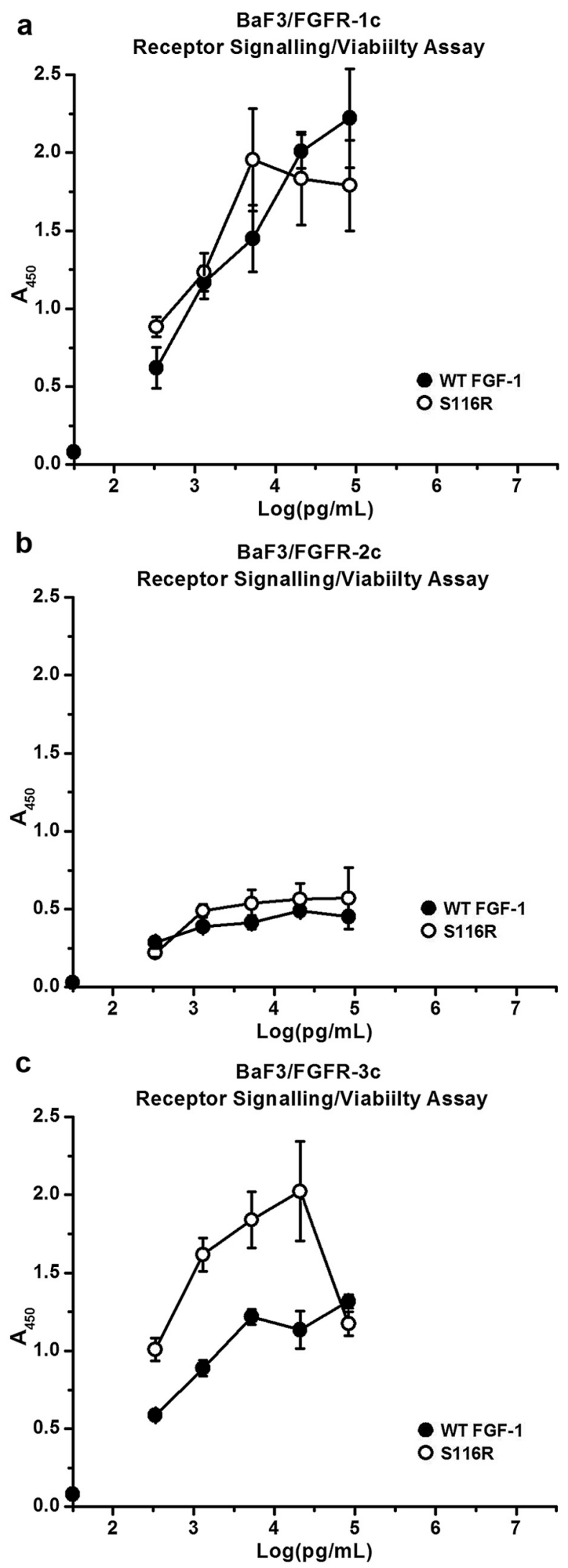

Figure 6. BaF3/FGFR signaling/cell viability assay of WT FGF-1 and S116R mutant protein. (a) Dose-response curve with BaF3/FGFR-1c cells. (b) Dose-response curve with BaF3/FGFR-2c cells. (c) Dose-response curve with BaF3/FGFR-3c cells. The soluble tetrazolium salt absorbance at $0 \mathrm{pg} / \mathrm{mL}$ protein concentration is indicated by data points on the ordinate. 


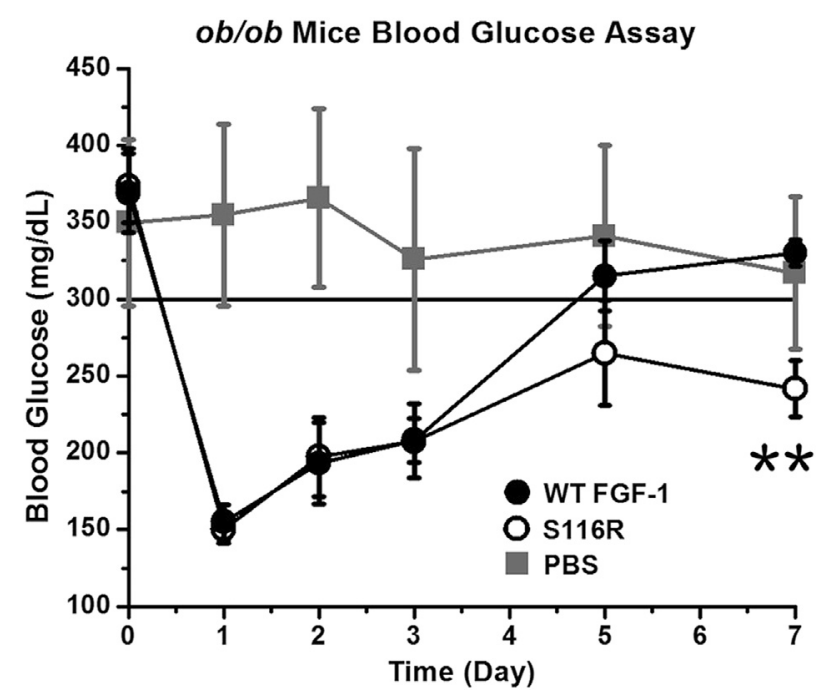

Figure 7. Blood glucose concentration in $o b / o b$ mice. Mice were administered $0.5 \mathrm{mg} / \mathrm{kg}$ subcutaneous injection of WT FGF-1, S116R mutant protein, or vehicle (PBS) $\left({ }^{* *} p=0.015\right)$. The horizontal line at $300 \mathrm{mg} / \mathrm{dL}$ indicates the cutoff for a mature onset hyperglycemic phenotype. All error bars are SEM.

regulation by phosphorylation and the primary functional effect on measured cell viability is receptor signaling. Thus, the increase in activity in the BaF3/FGFR-1c and BaF3/FGFR-3c cell assay with S116R is therefore interpreted as a direct enhancement of receptor signaling. The basis of this enhanced signaling may be due to increased efficiency of assembly of the ternary FGF/FGFR/HS signal transduction complex. Because HS affinity is unchanged between WT FGF-1 and S116R, this indicates that any enhanced affinity is likely between S116R and FGFR-1C and FGFR-2c. At the time of this writing, the PDB contains 4 depositions of FGF|FGFR|HS ternary complexes. The environment of FGF position 116 in each of these complexes is significantly different (Supplementary Fig. S5); furthermore, there remains significant debate regarding the biological relevance of each structure. ${ }^{16,80-83}$ The 1FQ9 crystal structure is the "symmetric" ternary complex, comprised of a 2:2:2 stoichiometry of FGF-2|FGFR-1|HS hexamer fragment. ${ }^{81}$ An overlay of S116R onto this structure indicates that the S116R mutation is exposed to bulk solvent. No other intermolecular interaction between S116R or FGFR moiety occurs (Supplementary Fig. S5A). The 1E00 crystal structure is the "asymmetric" ternary complex, comprised of a 2:2:1 stoichiometry of FGF-1|FGFR-2|HS decamer fragment. ${ }^{16}$ An overlay of S116R onto this structure indicates that the S116R mutation is also exposed to bulk solvent (Supplementary Fig. S5B). The 3CU1 crystal structure includes FGF-1 complexed with FGFR-2 (D2 domain only) and 2 SOS molecules in a 2:2:2 stoichiometry (Supplementary Fig. S5C). The D3 domains in this figure are modeled based on the conserved structure of the FGF|FGFR complex present in all 9 structural depositions of FGFs in complex with FGFR ectodomains. An overlay of S116R onto this structure indicates that the S116R mutant side chain is oriented toward the D2* domain of the paired FGF|FGFR dimer in the ternary complex (asterisk indicating that the FGFR interaction is with the FGFR of the adjacent FGF/FGFR pair). Specifically, the 116R side chain is $4.4 \AA$ distal to Gln212* of FGFR-2; however, this contact distance is not close enough to permit any direct hydrogen bonding. The 30JV crystal structure includes FGF-1 complexed with FGFR-1c (D2 and D3 domains) and an HS hexameric fragment in a 2:2:1 stoichiometry ${ }^{10}$ (Supplementary Fig. S5D). An overlay of S116R onto this structure shows that the mutant S116R is also oriented toward the D2* domain of the paired FGF|FGFR dimer in the ternary complex (although not the same D2* neighbor contact as in 3CU1). Remarkably, the mutant $116 \mathrm{R}$ side chain is ideally positioned to form both a charged $\mathrm{H}$-bond with S157* and a salt bridge with Glu159* of FGFR-1c in the paired FGF|FGFR dimer (Fig. 8). In this regard, positions 157 and 159 in FGFR-2c are both T, and a similar favorable FGF-1|FGFR-2c* interaction would not be present. Thus, the features of the 30JV ternary complex provide a structural basis for enhanced FGF|FGFR-1 dimerization with the S116R mutation (in addition to suggesting why such enhancement

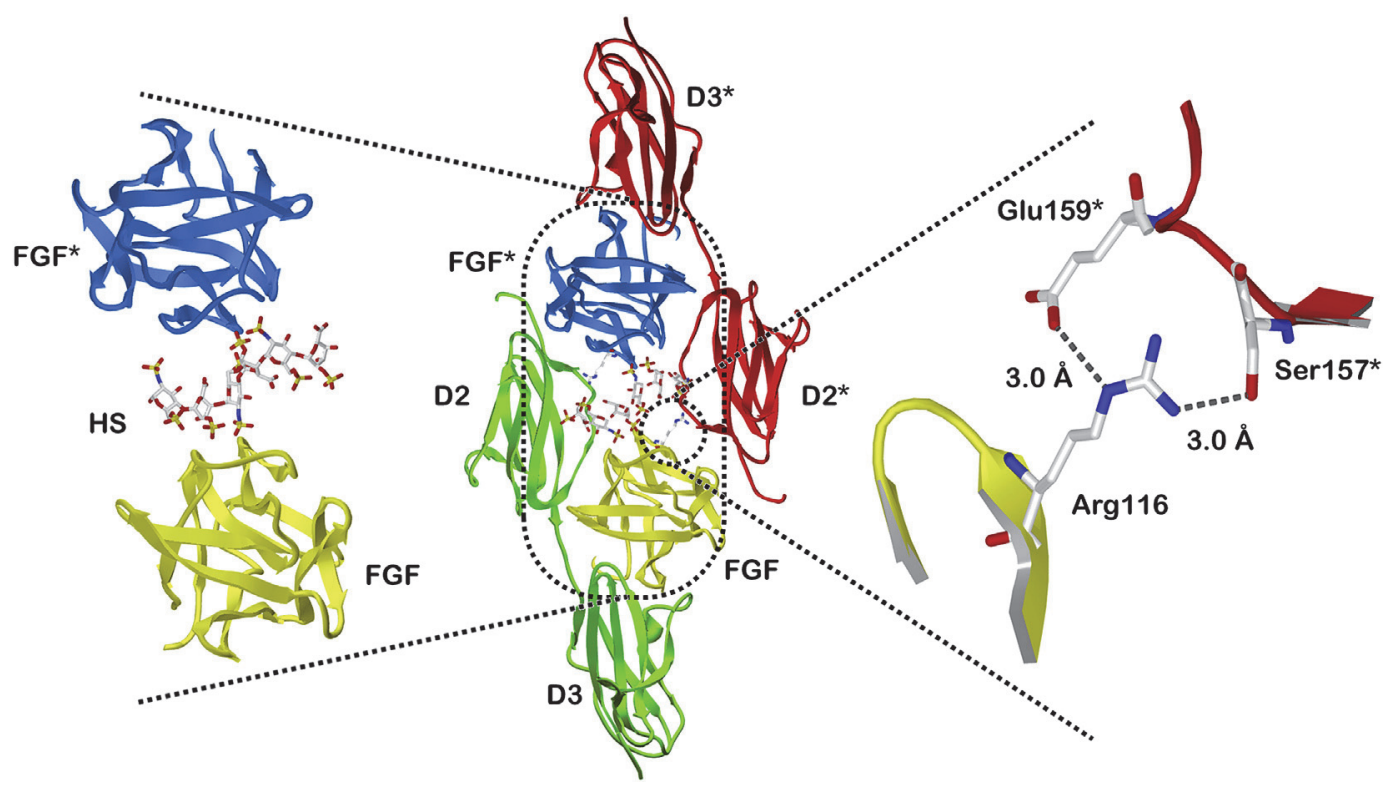

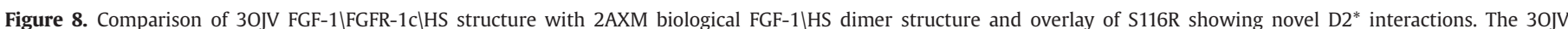

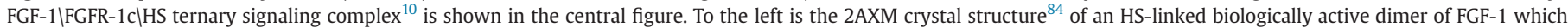

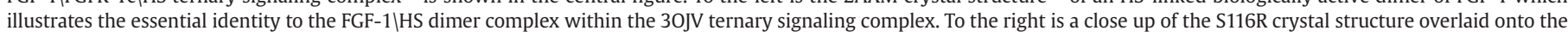

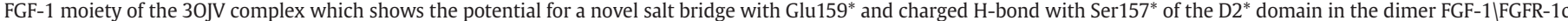
dimer interface. A similar interaction is possible with FGFR-3c and the structurally equivalent Glu 157. 
is not observed with FGFR-2c). An X-ray structure has been reported for FGF-1/FGFR-3c monomer assembly (PDB accession $1 \mathrm{RY7}$ ) and shows that Glu 157 is structurally equivalent to Glu159 in FGFR-1c; thus, the enhanced BaF3/FGFR-3c stimulation by S116R (Fig. 6c) is also consistent with the hypothesis of a novel receptor dimerization interaction.

However, the 30JV complex structure is not favored as a functional signal transduction assembly because the distance between the inferred intracellular tyrosine kinases is too great to permit efficient cross-phosphorylation, ${ }^{10}$ although the reports of different crystal structures for the FGF/FGFR signal transduction complex strongly suggests the potential for a structurally dynamic assembly process. Furthermore, FRET studies indicate that FGFR-1c forms dimeric assemblies in the membrane prior to FGF binding (although the structural details of such dimers are unknown, they have non-active tyrosine kinase moieties). ${ }^{85}$ The present results are therefore consistent with S116R promoting initial assembly of the FGFR-1c signal transduction complex (as represented by the 30JV structure) by enhancement of FGF-1/FGFR* dimer interface interactions (for FGFR-1c and FGFR-3c). Such an assembly complex may undergo subsequent structural rearrangement to produce a competent signal transduction assembly (represented by $1 \mathrm{FQ} 9$ or 1E0O structures).

The diminished mitogenic activity of S116R compared to WT FGF-1 in NIH 3T3 cells versus the enhanced activity of S116R compared to WT FGF-1 in the BaF3/FGFR-1c system is notable. The $\mathrm{NIH}$ 3T3 assay is keenly sensitive to any exogenously added HS which stimulates the assay (reducing $\mathrm{EC}_{50}$, but not altering the maximal stimulation ${ }^{29}$ ); thus, this assay would also be sensitive to mutant changes in HS affinity; however, characterization of the SOS-binding properties and heparin sulfate analytical chromatography demonstrate no significant alteration in HS affinity for the S116R mutant compared to WT FGF-1. The NIH 3T3 mitogenic activity assay involves the full combination of receptor stimulation and subsequent intracrine activity, while the BaF3 assay principally quantifies receptor stimulation. In this regard, the diminished 3T3 fibroblast mitogenic activity of S116R compared to WT FGF-1 indicates that intracrine function associated with phosphorylation is important for full FGF-1 mitogenic activity. The inability of S116R to undergo phosphorylation, and subsequent reduction in mitogenic activity, is most consistent with reports that describe nuclear transport and enhanced nuclear retention driven by phosphorylation. ${ }^{45}$ The glucose-lowering effect of FGF-1 in $o b / o b$ mice is dependent on FGFR-1c activation in adipose tissue. ${ }^{86}$ Furthermore, antibody-mediated activation of FGFR-1 ameliorates type II diabetes $^{87}$; thus, intracrine activity of FGF-1 is independent of the glucose-lowering functionality. Systemic delivery of FGF-1 results in rapid sequestration on HS. ${ }^{27}$ The WT FGF-1 equivalent HS affinity and thermostability of S116R suggest unperturbed PK distribution and redistribution kinetics. ${ }^{27}$ Therefore, the prolonged activity of S116R compared to WT FGF-1 in glucose regulation in ob/ob mice is consistent with enhanced stimulation of FGFR-1c after latent release from HS sequestration. The decreased NIH 3T3 fibroblast mitogenic activity, but increased glucose-lowering activity in $o b / o b$ mice indicates that these functionalities are separable, and S116R might be further mutated to yield a form with enhanced glucose-lowering effect and diminished mitogenic activity. Such a mutant form would be a potentially advantageous and novel insulin sensitizer to treat metabolic disorder.

\section{Acknowledgments}

We thank Dr Thayumanasamy Somasundaram for technical assistance with X-ray diffraction data collection. Data were collected at Southeast Regional Collaborative Access Team 22-BM beamline at the Advanced Photon Source, Argonne National Laboratory. Supporting institutions may be found at www.ser-cat.org/ members.html. Use of the Advanced Photon Source was supported by the U. S. Department of Energy,Office of Science, Office of Basic Energy Sciences, under Contract No. W-31-109-Eng-38. We also acknowledge the instrumentation resources of the Biomedical Proteomics Laboratory, College of Medicine. This work was supported by the Florida State University Research Foundation and College of Medicine. R.M.E. is an HHMI Investigator at the Salk Institute and March of Dimes Chair, and is supported by NIH grant (DK057978) and the Leona M. and Harry B. Helmsley Charitable Trust. Additional research support funds were provided by Trefoil 02 Therapeutics, LLC.

\section{References}

1. Ornitz DM. FGF signaling in the developing endochondral skeleton. Cytokine Growth Factor Rev. 2005;16(2):205-213.

2. Kuro-o M. Endocrine FGFs and Klothos: emerging concepts. Trends Endocrinol Metab. 2008;19(7):239-245.

3. Beenken A, Mohammadi M. The FGF family: biology, pathophysiology and therapy. Nat Rev Drug Discov. 2009;8(3):235-253.

4. Suh JM. Endocrinization of FGF1 produces a neomorphic and potent insulin sensitizer. Nature. 2014;513(7518):436-439.

5. Grose R, Turner N. Fibroblast growth factor signalling: from development to cancer. Nat Rev Cancer. 2010;10(2):116-129.

6. Ornitz DM, Xu J, Colvin JS, et al. Receptor specificity of the fibroblast growth factor family. J Biol Chem. 1996;271(25):15292-15297.

7. Zhang $X$, Ibrahimi OA, Olsen SK, Umemori $H$, Mohammadi M, Ornitz DM. Receptor specificity of the fibroblast growth factor family: the complete mammalian FGF family. J Biol Chem. 2006;281(23):15694-15700.

8. Copeland RA, Ji H, Halfpenny AJ, et al. The structure of human acidic fibroblast growth factor and its interaction with heparin. Arch Biochem Biophys. 1991;289(1):53-61.

9. Blaber SI, Culajay JF, Khurana A, Blaber M. Reversible thermal denaturation of human FGF-1 induced by low concentrations of guanidine hydrochloride. Biophys J. 1999;77:470-477.

10. Beenken A, Eliseenkova AV, Ibrahimi OA, Olsen SK, Mohammadi M. Plasticity in interactions of fibroblast growth factor 1 (FGF1) N terminus with FGF receptors underlies promiscuity of FGF1. J Biol Chem. 2012;287(5):3067-3078.

11. Ornitz DM, Itoh N. The fibroblast growth factor signaling pathway. Wiley Interdiscip Rev Dev Biol. 2015;4(3):215-266.

12. Rapraeger AC, Krufka A, Olwin BB. Requirement of heparan sulfate for BFGFmediated fibroblast growth and myoblast differentiation. Science. 1991;252: 1705-1708.

13. Yayon A, Klagsbrun M, Esko JD, Leder P, Ornitz DM. Cell surface, heparin-like molecules are required for binding of basic fibroblast growth factor to its high affinity receptor. Cell. 1991;64:841-848.

14. Spivak-Kroizman T, Lemmon MA, Dikic I, et al. Heparin-induced oligomerization of FGF molecules is responsible for FGF receptor dimerization, activation and cell proliferation. Cell. 1994;79:1015-1024.

15. Xu R, Ori A, Rudd TR, et al. Diversification of the structural determinants of fibroblast growth factor-heparin interactions: implications for binding specificity. J Biol Chem. 2012;287(47):40061-40073.

16. Pellegrini L, Burke DF, von Delft F, Mulloy B, Blundell TL. Crystal structure of fibroblast growth factor receptor ectodomain bound to ligand and heparin. Nature. 2000;407(6807):1029-1034.

17. Canales A, Lozano R, López-Méndez B, et al. Solution NMR structure of a human FGF-1 monomer, activated by a hexasaccharide heparin-analogue. FEBS $J$. 2006;273(20):4716-4727.

18. Blow DM, Janin J, Sweet RM. Mode of action of soybean trypsin inhibitor (Kunitz) as a model for specific protein-protein interactions. Nature. 1974;249: 54-57.

19. Zhu X, Komiya H, Chirino A, et al. Three-dimensional structures of acidic and basic fibroblast growth factors. Science. 1991;251:90-93.

20. Murzin AG, Lesk AM, Chothia C. $\beta$-Trefoil fold. Patterns of structure and sequence in the kunitz inhibitors interleukins- $1 \beta$ and $1 \alpha$ and fibroblast growth factors. J Mol Biol. 1992;223:531-543.

21. Blaber M, DiSalvo J, Thomas KA. X-ray crystal structure of human acidic fibroblast growth factor. Biochemistry. 1996;35:2086-2094.

22. Brych SR, Dubey VK, Bienkiewicz E, Lee J, Logan TM, Blaber M. Symmetric primary and tertiary structure mutations within a symmetric superfold: a solution, not a constraint, to achieve a foldable polypeptide. J Mol Biol. 2004;344(3):769-780.

23. Longo L, Lee J, Blaber M. Experimental support for the foldability-function tradeoff hypothesis: segregation of the folding nucleus and functional regions in FGF-1. Protein Sci. 2012;21(12):1911-1920.

24. Rosengart TK, Kuperschmid JP, Maciag T, Clark RE. Pharmacokinetics and distribution of heparin-binding growth factor-1 (endothelial cell growth factor) in the rat. Circ Res. 1989;64:227-234. 
25. Hondermarck H, Courty J, Boilly B, Thomas D. Distribution of intravenously administered acidic and basic fibroblast growth factors in mouse. Experientia. 1990;46:973-974

26. Zinn KR, Kelpke S, Chaudhuri TR, Sugg T, Mountz JM, Thompson JA. Imaging Tc-99m-labeled FGF-1 targeting in rats. Nucl Med Biol. 2000;27: 407-414.

27. Xia X, Babcock JP, Blaber SI, Harper KM, Blaber M. Pharmacokinetic properties of 2nd-generation fibroblast growth factor-1 mutants for therapeutic application. PLoS One. 2012;7(11):e48210.

28. Gimenez-Gallego G, Conn G, Hatcher VB, Thomas KA. The complete amino acid sequence of human brain-derived acidic fibroblast growth factor. Biochem Biophys Res Commun. 1986;128(2):611-617.

29. Lee J, Blaber M. The interaction between thermodynamic stability and buried free cysteines in regulating the functional half-life of fibroblast growth factor1. J Mol Biol. 2009;393:113-127.

30. Lee J, Blaber M. Increased functional half-life of fibroblast growth factor- 1 by recovering a vestigial disulfide bond. J Proteins Proteomics. 2010;1:37-42.

31. Chen G, Gulbranson DR, Yu P, Hou Z, Thomson JA. Thermal stability of fibroblast growth factor protein is a determinant factor in regulating self-renewal, differentiation, and reprogramming in human pluripotent stem cells. Stem Cells. 2012;30(4):623-630.

32. Mignatti P, Rifkin DB. Release of basic fibroblast growth factor, an angiogenic factor devoid of secretory signal sequence: a trivial phenomenon or a novel secretion mechanism? J Cell Biochem. 1991;47:201-207.

33. Mignatti P, Morimoto T, Rifkin DB. Basic fibroblast growth factor, a protein devoid of secretory signal sequence, is released by cells via a pathway independent of the endoplasmic reticulum-Golgi complex. J Cell Physiol. 1992;151(1):81-93.

34. Florkiewicz RZ, Majack RA, Buechler RD, Florkiewicz E. Quantitative export of FGF-2 occurs through an alternative, energy-dependent, non-ER/Golg pathway. J Cell Physiol. 1995;162(3):388-399.

35. Mach $\mathrm{H}$, Middaugh $\mathrm{CR}$. Interaction of partially structured states of acidic fibroblast growth factor with phospholipid membranes. Biochemistry. 1995;34: 9913-9920.

36. Olsnes S, Klingenberg O, Wiedłocha A. Transport of exogenous growth factors and cytokines to the cytosol and to the nucleus. Physiol Rev. 2003;83(1):163182.

37. Sørensen V, Wiedlocha A, Haugsten EM, Khnykin D, Wesche J, Olsnes S Different abilities of the four FGFRs to mediate FGF-1 translocation are linked to differences in the receptor C-terminal tail. J Cell Sci. 2006;119(20):43324341.

38. Lin YZ, Yao SY, Hawiger J. Role of the nuclear localization sequence in fibroblast growth factor-1-stimulated mitogenic pathways. J Biol Chem. 1996;271:53055308.

39. Wesche J, Małecki J, Wiedłocha A, et al. Two nuclear localization signals required for transport from the cytosol to the nucleus of externally added FGF1 translocated into cells. Biochemistry. 2005;44(16):6071-6080.

40. Wiedlocha A, Falnes PO, Madshus IH, Sandvig K, Olsnes S. Dual mode of signal transduction by externally added acidic fibroblast growth factor. Cell. 1994;76(6):1039-1051.

41. Rodriguez-Enfedaque A, Bouleau S, Laurent M, et al. FGF1 nuclear translocation is required for both its neurotrophic activity and its p53-dependent apoptosis protection. Biochim Biophys Acta. 2009;1793(11):1719-1727.

42. Delmas E, Jah N, Pirou C, et al. FGF1 C-terminal domain and phosphorylation regulate intracrine FGF1 signaling for its neurotrophic and anti-apoptotic activities. Cell Death Dis. 2016;7:e2079.

43. Klingenberg $\mathrm{O}, \mathrm{Wi}$ IJdłocha $\mathrm{A}$, Olsnes S. Effects of mutations of a phosphorylation site in an exposed loop in acidic fibroblast growth factor. $J$ Biol Chem 1999;274(25):18081-18086.

44. Więdłocha A, Nilsen T, Wesche J, et al. Phosphorylation-regulated nucleocytoplasmic trafficking of internalized fibroblast growth factor-1. Mol Biol Cell. 2005;16(2):794-810.

45. Guillonneau X, Regnier-Ricard F, Dupuis C, Courtois Y, Mascarelli F. Paracrine effects of phosphorylated and excreted FGF1 by retinal pigmented epithelial cells. Growth Factors. 1998;15(2):95-112.

46. Sletten T, Kostas M, Bober J, et al. Nucleolin regulates phosphorylation and nuclear export of fibroblast growth factor 1 (FGF1). PLoS One. 2014;9(3): e90687.

47. Jonker JW, Suh JM, Atkins AR, et al. A PPAR[ggr]-FGF1 axis is required for adaptive adipose remodelling and metabolic homeostasis. Nature. 2012:485(7398):391-394.

48. Klingenberg O, Wiedlocha A, Rapak A, Muñoz R, Falnes PØ, Olsnes S Inability of the acidic fibroblast growth factor mutant K132E to stimulate DNA synthesis after translocation into cells. J Biol Chem. 1998;273(18): 11164-11172.

49. Burgess WH, Shaheen AM, Ravera M, Jaye M, Donohue PJ, Winkles JA. Possible dissociation of the heparin-binding and mitogenic activities of heparin-binding (acidic fibroblast) growth factor- 1 from its receptor-binding activities by sitedirected mutagenesis of a single lysine residue. J Cell Biol. 1990;111(5):21292138.

50. Culajay JF. Thermodynamic Characterization of Mutations of Human Acidic Fibroblast Growth Factor Chemistry. Tallahassee, FL: Florida State University; 2000:59.

51. Fukuchi-Shimogori T, Grove EA. Neocortex patterning by the secreted signaling molecule FGF8. Science. 2001;294(5544):1071-1074.
52. Garel S, Huffman KJ, Rubenstein JLR. Molecular regionalization of the neocortex is disrupted in Fgf8 hypomorphic mutants. Development. 2003;130(9):1903 1914.

53. McWilliam H, Li W, Uludag M, et al. Analysis tool web services from the EMBLEBI. Nucleic Acids Res. 2013;41(W1):W597-W600.

54. Brych SR, Blaber SI, Logan TM, Blaber M. Structure and stability effects of mutations designed to increase the primary sequence symmetry within the core region of a $\beta$-trefoil. Protein Sci. 2001;10:2587-2599.

55. Kim J, Brych SR, Lee J, Logan TM, Blaber M. Identification of a key structural element for protein folding within $\beta$-hairpin turns. J Mol Biol. 2003;328:951961.

56. Tsai PK, Volkin DB, Dabora JM, et al. Formulation design of acidic fibroblast growth factor. Pharm Res. 1993;10(5):649-659.

57. Zazo M, Lozano RM, Ortega S, et al. High-level synthesis in Escherichia coli of a shortened and full-length human acidic fibroblast growth factor and purification in a form stable in aqueous solutions. Gene. 1992;113:231-238.

58. Eftink MR. The use of fluorescence methods to monitor unfolding transitions in proteins. Biophys J. 1994;66:482-501.

59. Pace $\mathrm{CN}$, Scholtz JM. Measuring the conformational stability of a protein. In: Creighton TE, ed. Protein Structure: A Practical Approach. Oxford: Oxford University Press; 1997:299-321.

60. Kim JJ, Iyer V, Joshi SB, Volkin DB, Middaugh CR. Improved data visualization techniques for analyzing macromolecule structural changes. Protein Sci. 2012;21:1540-1553.

61. Otwinowski Z, Minor W. Processing of x-ray diffraction data collected in oscillation mode. Methods Enzymol. 1997;276:307-326.

62. Terwilliger TC, Grosse-Kunstleve RW, Afonine PV, et al. Iterative model building, structure refinement and density modification with the PHENIX AutoBuild wizard. Acta Crystallogr D Biol Crystallogr. 2008;64:61-69.

63. Zwart PH, Afonine PV, Grosse-Kunstleve RW, et al. Automated structure solution with the PHENIX suite. Methods Mol Biol. 2008;426:419-435.

64. Emsley P, Cowtan K. Coot: model-building tools for molecular graphics. Acta Crystallogr D Biol Crystallogr. 2004;60:2126-2132.

65 . Brunger AT. Free $R$ value: a novel statistical quantity for assessing the accuracy of crystal structures. Nature. 1992;355:472-475

66. Dubey VK, Lee J, Somasundaram T, Blaber S, Blaber M. Spackling the crack: stabilizing human fibroblast growth factor- 1 by targeting the $\mathrm{N}$ and $\mathrm{C}$ terminus beta-strand interactions. J Mol Biol. 2007;371(1):256-268.

67. Ornitz DM, Yayon A, Flanagan JG, Svahn CM, Levi E, Leder P. Heparin is required for cell-free binding of basic fibroblast growth factor to a soluble receptor and for mitogenesis in whole cells. Mol Cell Biol. 1992;12:240-247.

68. Collins MKL, Downward J, Miyajima A, Maruyama K, Arai KI, Mulligan RC. Transfer of functional EGF receptors to an IL3-dependent cell line. J Cell Physiol. 1988;137(2):293-298

69. Wang JK, Gao G, Goldfarb M. Fibroblast growth factor receptors have different signaling and mitogenic potentials. Mol Cell Biol. 1994;14(1):181-188.

70. Fan H, Li H, Zhang M, Middaugh CR. Effects of solutes on empirical phase diagrams of human fibroblast growth factor 1. J Pharm Sci. 2007:95:1490-1503.

71. Kim JW, Blaber SI, Blaber M. Alternative type I and I' turn conformations in the $\beta 8 / \beta 9 \beta$-hairpin of human acidic fibroblast growth factor. Protein Sci. 2002;11: 459-466.

72. Bernett MJ, Somasundaram T, Blaber M. An atomic resolution structure for human fibroblast growth factor 1. Proteins. 2004;57(3):626-634.

73. Hu YP, Zhong YQ Chen ZG, et al. Divergent synthesis of 48 heparan sulfatebased disaccharides and probing the specific sugar-fibroblast growth factor1 interaction. J Am Chem Soc. 2012;134(51):20722-20727.

74. Mathieu M, Chatelain E, Ornitz D, et al. Receptor binding and mitogenic properties of mouse fibroblast growth factor 3. J Biol Chem. 1995;270:2419724203.

75. Tashiro E, Minato Y, Maruki H, Asagiri M, Imoto M. Regulation of FGF receptor2 expression by transcription factor E2F-1. Oncogene. 2003:22(36):5630-5635.

76. Kurulgan Demirci E, Demirci T, Trzewik J, et al. Genome-wide gene expression analysis of NIH 3T3 cell line under mechanical stimulation. Cell Mol Bioeng. 2010;4(1):46-55.

77. Sahni M, Ambrosetti DC, Mansukhani A, Gertner R, Levy D, Basilico C. FGF signaling inhibits chondrocyte proliferation and regulates bone development through the STAT-1 pathway. Genes Dev. 1999;13(11):1361-1366.

78. Linemeyer DL, Kelly LJ, Menke JG, Gimenez-Gallego G, DiSalvo J, Thomas KA Expression in Escherichia coli of a chemically synthesized gene for biologically active bovine acidic fibroblast growth factor. Biotechnology. 1987;5: 960-965.

79. Mellin TN, Mennie RJ, Cashen DE, et al. Acidic fibroblast growth factor accelerates dermal wound healing. Growth Factors. 1992;7:1-14.

80. Plotnikov AN, Schlessinger J, Hubbard SR, Mohammadi M. Structural basis for FGF receptor dimerization and activation. Cell. 1999;98(5):641-650.

81. Schlessinger J, Plotnikov AN, Ibrahimi OA, et al. Crystal structure of a ternary FGF-FGFR-heparin complex reveals a dual role for heparin in FGFR binding and dimerization. Mol Cell Biol. 2000;6:743-750.

82. Harmer NJ, Ilag LL, Mulloy B, Pellegrini L, Robinson CV, Blundell TL. Towards a resolution of the stoichiometry of the fibroblast growth factor (FGF)-FGF receptor-heparin complex. J Mol Biol. 2004;339(4):821-834.

83. Ibrahimi OA, Yeh BK, Eliseenkova AV, et al. Analysis of mutations of fibroblast growth factor (FGF) and a pathogenic mutation in FGF receptor (FGFR) provides direct evidence for the symmetric two-end model for FGFR dimerization. Mol Cell Biol. 2005;25:671-684. 
84. DiGabriele AD, Lax I, Chen DI, et al. Structure of a heparin-linked biologically active dimer of fibroblast growth factor. Nature. 1998;393(6687): 812-817.

85. Comps-Agrar L, Dunshee DR, Eaton DL, Sonoda J. Unliganded fibroblast growth factor receptor 1 forms density-independent dimers. J Biol Chem. 2015;290: 24166-24177.
86. Liu W, Struik D, Nies VJM, et al. Effective treatment of steatosis and steatohepatitis by fibroblast growth factor 1 in mouse models of nonalcoholic fatty liver disease. Proc Natl Acad Sci U S A. 2016;113(8):2288-2293.

87. Wu AL, Kolumam G, Stawicki S, et al. Amelioration of type 2 diabetes by antibody-mediated activation of fibroblast growth factor receptor 1. Sci Trans Med. 2011;3(113):113ra126. 